\title{
Inflammatory tumour cell killing by oncolytic reovirus for the treatment of melanoma
}

\author{
F Errington ${ }^{1}$, CL White ${ }^{2}$, KR Twigger ${ }^{2}$, A Rose ${ }^{1}, \mathrm{~K} \mathrm{Scott}^{1}$, L Steele ${ }^{1}$, LJ Ilett ${ }^{1}$, R Prestwich ${ }^{1}$, HS Pandha ${ }^{3}$, \\ $\mathrm{M} \mathrm{Coffey}^{4}$, P Selby ${ }^{1}$, R Vile ${ }^{5}$, KJ Harrington ${ }^{2,6,7}$ and AA Melcher ${ }^{1,7}$ \\ ${ }^{1}$ Cancer Research UK Clinical Centre, St James's University Hospital, University of Leeds, Leeds, UK; ${ }^{2}$ Targeted Therapy Laboratory, \\ Chester Beatty Laboratories, Institute of Cancer Research, Cancer Research UK Centre for Cell and Molecular Biology, London, UK; \\ ${ }^{3}$ Postgraduate Medical School, University of Surrey, Guildford, UK; ${ }^{4}$ Oncolytics Biotech Inc., Calgary, Canada; ${ }^{5}$ Mayo Clinic, Rochester, \\ MN, USA and ${ }^{6} \mathrm{Head}$ and Neck Unit, Royal Marsden Hospital, London, UK
}

\begin{abstract}
Reovirus is a promising unmodified double-stranded RNA (dsRNA) anti-cancer oncolytic virus, which is thought to specifically target cells with activated Ras. Although reovirus has been tested in a wide range of preclinical models and has entered early clinical trials, it has not previously been tested for the treatment of human melanoma. Here, we show that reovirus effectively kills and replicates in both human melanoma cell lines and freshly resected tumour; intratumoural injection also causes regression of melanoma in a xenograft in vivo model. Reovirus-induced melanoma death is blocked by caspase inhibition and is dependent on constituents of the Ras/RalGEF/p38 pathway. Reovirus melanoma killing is more potent than, and distinct from,
\end{abstract}

chemotherapy or radiotherapy-induced cell death; a range of inflammatory cytokines and chemokines are released by infected tumour cells, while IL-10 secretion is abrogated. Furthermore, the inflammatory response generated by reovirus-infected tumour cells causes bystander toxicity against reovirus-resistant tumour cells and activates human myeloid dendritic cells (DC) in vitro. Hence, reovirus is suitable for clinical testing in melanoma, and may provide a useful danger signal to reverse the immunologically suppressive environment characteristic of this tumour.

Gene Therapy (2008) 15, 1257-1270; doi:10.1038/gt.2008.58; published online 10 April 2008

Keywords: melanoma; reovirus; oncolytic virus; inflammatory cytokines

\section{Introduction}

Reovirus is a non-enveloped double-stranded RNA (dsRNA) virus of the Reoviridae family, which ubiquitously infects target cells, but is essentially non-pathogenic in humans. It is highly prevalent in the general population, with $50-60 \%$ of adults testing positive for reovirus-specific antibodies. ${ }^{1}$ The virus is currently under investigation as an anti-cancer agent, as it targets and replicates only in tumour cells with activation of the Ras signalling pathway. ${ }^{2,3}$ This selectivity is thought to arise because Ras-activated tumour cells cannot autophosphorylate PKR in response to the virus; this prevents phosphorylation of eukaryotic initiation factor- $2 \alpha$, which blocks initiation of translation of viral genes in normal cells. Since permissive reovirus replication is also a feature of cells with defects in pathways lying up or downstream of the Ras proteins themselves, this implicates a significant proportion of human tumours as potentially susceptible to reoviral oncolysis. ${ }^{4,5}$ More recent studies have suggested that the determinants of

Correspondence: Professor AA Melcher, Cancer Research UK Clinical Centre, St James's University Hospital, University of Leeds, Beckett Street, Leeds LS9 7TF, UK.

E-mail: a.a.melcher@leeds.ac.uk

${ }^{7}$ Joint senior authors.

Received 20 September 2007; revised 21 February 2008; accepted 23 February 2008; published online 10 April 2008 susceptibility to reovirus-induced cell death may be more complex than simple generic activation of the Ras signalling pathway. Norman et al. ${ }^{6}$ reported that the activity of the Ras/RalGEF/p38 pathway is the major determinant of susceptibility in transformed NIH 3T3 cells; other work has suggested that Ras activation status does not affect reovirus replication in C26 murine colorectal cancer cells, but does influence their sensitivity to reovirus-induced apoptosis. ${ }^{7}$ Viral uncoating and proteolytic disassembly may also play critical roles in effective oncolysis. , $^{8}$

In preclinical studies, reovirus has been delivered by intratumoural, intravenous or intraperitoneal routes and has shown activity in a wide range of models. These include breast, ovarian, colon, prostate and glioma tumour systems, as well as haematological malignancies, thus confirming the broad potential of reovirus as an anti-cancer agent. ${ }^{10-13}$ Thus far, early phase clinical trials have been completed or are ongoing in prostate cancer, glioma and advanced adult solid malignancies, with no evidence of significant toxicity following intratumoural or intravenous delivery (Vidal et al., unpublished data).

Although a significant percentage of melanomas are defective in Ras or associated signalling pathways, ${ }^{14,15}$ reovirus has not previously been tested against this disease. Melanoma is an increasing clinical problem, with incidence rates across the world approximately doubling over the last 10 years. Although patients with 
thin primary melanomas are usually cured by surgical resection alone, advanced disease has a very poor prognosis with a median survival of less than 1 year. Standard systemic treatment with chemotherapy and/or cytokine therapy has limited efficacy ${ }^{16}$ and novel approaches are urgently needed; hence melanoma represents an appropriate target for assessment of reovirus as an oncolytic agent.

As well as the direct oncolytic potential of the virus, there are features of reovirus-induced cell killing, which may lead to additional bystander immune activation against the tumour. As previously described for other agents, such as herpes simplex virus, ${ }^{17}$ vaccinia virus, ${ }^{18}$ vesicular stomatitis virus ${ }^{19}$ and Newcastle disease virus $^{20}$ viral infection of target tumour cells may enhance recognition by the immune system and help prime generation of an anti-tumour response. If dying tumour cells express tumour-associated antigens (TAAs), which are released in the context of infection, the response against the virus may facilitate coincident innate and subsequent specific priming against TAAs as well as viral epitopes. ${ }^{21}$ However, the immune response can inhibit as well as augment therapy during viral oncolysis. Anti-viral antibody responses in particular are likely to restrict activity on repeat administration; indeed, there is evidence that blunting anti-viral antibodies can enhance the anti-tumour potency of reovirus, ${ }^{22}$ although completely unrestricted viral replication can also lead to concomitant normal tissue toxicity. ${ }^{23}$

In this study, we have tested reovirus against human melanoma in vitro using both cell lines and freshly resected tumour and in vivo in a xenograft model. We have also explored the mechanism of cell death, with special regard to the mode of melanoma killing by reovirus in comparison to current treatment modalities and its potential immunological consequences.

\section{Results}

\section{Susceptibility of human melanoma cell lines to reovirus-induced cytotoxicity in vitro}

The susceptibility of human melanoma cell lines to reovirus infection and oncolysis was first examined. Mel888, Mel-624, Mewo and Skmel-28 were left untreated or treated with $10 \mathrm{PFU} /$ cell reovirus and cell viability was examined 48 and $72 \mathrm{~h}$ post infection (Figure 1a). The viability of Mel-888, Mel-624 and Skmel-28 cells was significantly reduced at 48 and $72 \mathrm{~h}$ post infection ( $P \leqslant 0.05$ by Student's $t$-test). Although the viability of Mewo cells was reduced at $48 \mathrm{~h}$, this only became statistically significant $(P=0.0041) 72 \mathrm{~h}$ post infection. Examination of the morphology of all four untreated cell lines, compared with those infected with $10 \mathrm{PFU} /$ cell reovirus, revealed significant viral-induced cytopathic effect (CPE) at $48 \mathrm{~h}$ (Figure 1b). These data demonstrate that human melanoma cell lines are susceptible to reovirus-induced cell death in vitro.

Next, a more detailed analysis of the sensitivity of an extended panel of seven melanoma cell lines (Skmel-28, Mel-624, Mel-888, Mewo, Colo-829, A-375 and WM-266) and one normal melanocyte cell line (Melan-A) ${ }^{24}$ to reovirus cytotoxicity was conducted (Figure 1c). Three of the cell lines (Skmel-28, A-375 and WM-266) demon- strated exquisite sensitivity, whereas the other four cell lines showed more modest levels of reovirus-mediated cytotoxicity. Melan-A cells were resistant to reovirus even at dilutions of only 1:500 of the initial stock, equivalent to approximately $40 \mathrm{PFU} /$ cell (that is, fourfold higher than the dose of reovirus shown in Figure 1a to be cytotoxic against the melanoma cell lines, Mel-888, Mel-624, Mewo and Skeml-28). Hence, human melanoma cell lines are differentially sensitive to reovirus infection and oncolysis, but significantly more susceptible than normal melanocytes.

\section{Reovirus growth in human melanoma cell lines}

To determine whether reovirus replicated in melanoma cell lines, productive infection was assessed by western blot and plaque assays. Plaque assays were used to examine the production of infectious viral progeny in a panel of susceptible melanoma cell lines (Mel-888, Mel624, Mewo and Skmel-28) and non-susceptible normal melanocytes (Melan-A). All cells were infected with a known concentration of reovirus (10 PFU/cell) and cells/supernatants were harvested $72 \mathrm{~h}$ post infection. For each of the melanoma tumour cell lines, there was evidence of viral growth; in direct contrast, the normal melanocyte cell line, Melan-A failed to support viral replication with a fold change in viral titre of only 1.38 (Figure 2a). To further examine the kinetics of progeny virus production cells were infected with $10 \mathrm{PFU} /$ cell reovirus for $24,48,72$ or $96 \mathrm{~h}$ and viral replication determined by plaque assay; these experiments demonstrated significant viral replication $24 \mathrm{~h}$ after infection, reaching maximum levels at $48 \mathrm{~h}$ in all but one of the cell lines tested (Figure $2 b$ ). The absence of increasing levels of virus at later time points probably reflects the significant cell death observed by this stage.

The results demonstrated in Figures 1 and 2a suggest that reovirus replication does not correlate closely with cell sensitivity, as Mewo cells support significant viral replication, while being one of the least sensitive lines to viral killing. However, it is well documented that viral replication may not be required for reovirus-induced cell death; ${ }^{25-27}$ furthermore, studies from our laboratory have demonstrated that ultraviolet (UV)-inactivated, non-replicative reovirus induces significant, though reduced, cell death in these melanoma cell lines (data not shown). Hence, levels of viral replication and cytotoxicity are not inextricably linked.

To confirm the presence of viral proteins in cells which did support viral replication, whole cell lysates were processed 3, 8, 16, 24 and $48 \mathrm{~h}$ after reovirus treatment and expression of $\mu$, a capsid protein which constitutes $35 \%$ of the total viral protein, ${ }^{28}$ was examined by western blot (Figure 2b). Mel-624 and Skmel-28 cells, which were highly susceptible to reovirus-induced cell death, produced detectable levels of the $\mu$ protein just $16 \mathrm{~h}$ post infection. In contrast, reovirus protein was only detected in Mel-888 and Mewo cells 24 and $48 \mathrm{~h}$ post infection, respectively. Interestingly, Melan-A cells (which are not susceptible to reovirus-induced cell death (Figure 1c) and do not support viral replication (Figure 2a)) also showed increased expression of the $\mu$ outer capsid protein 16$48 \mathrm{~h}$ post infection (data not shown). While this finding appears to contradict a previous report suggesting that reovirus resistant cells are unable to translate viral transcripts, ${ }^{3}$ Marcato et al. ${ }^{9}$ have similarly shown that 

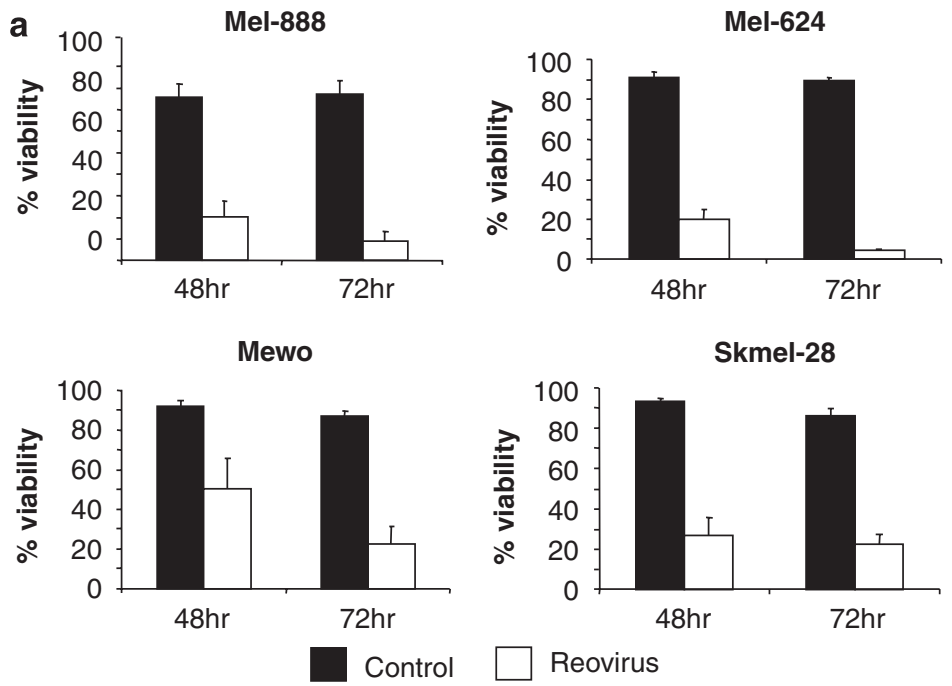

b
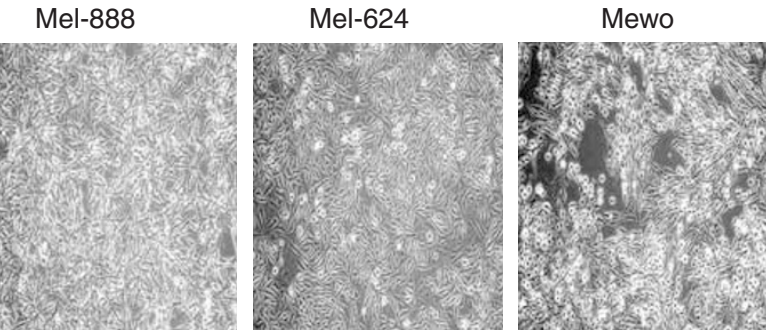

Skmel-28
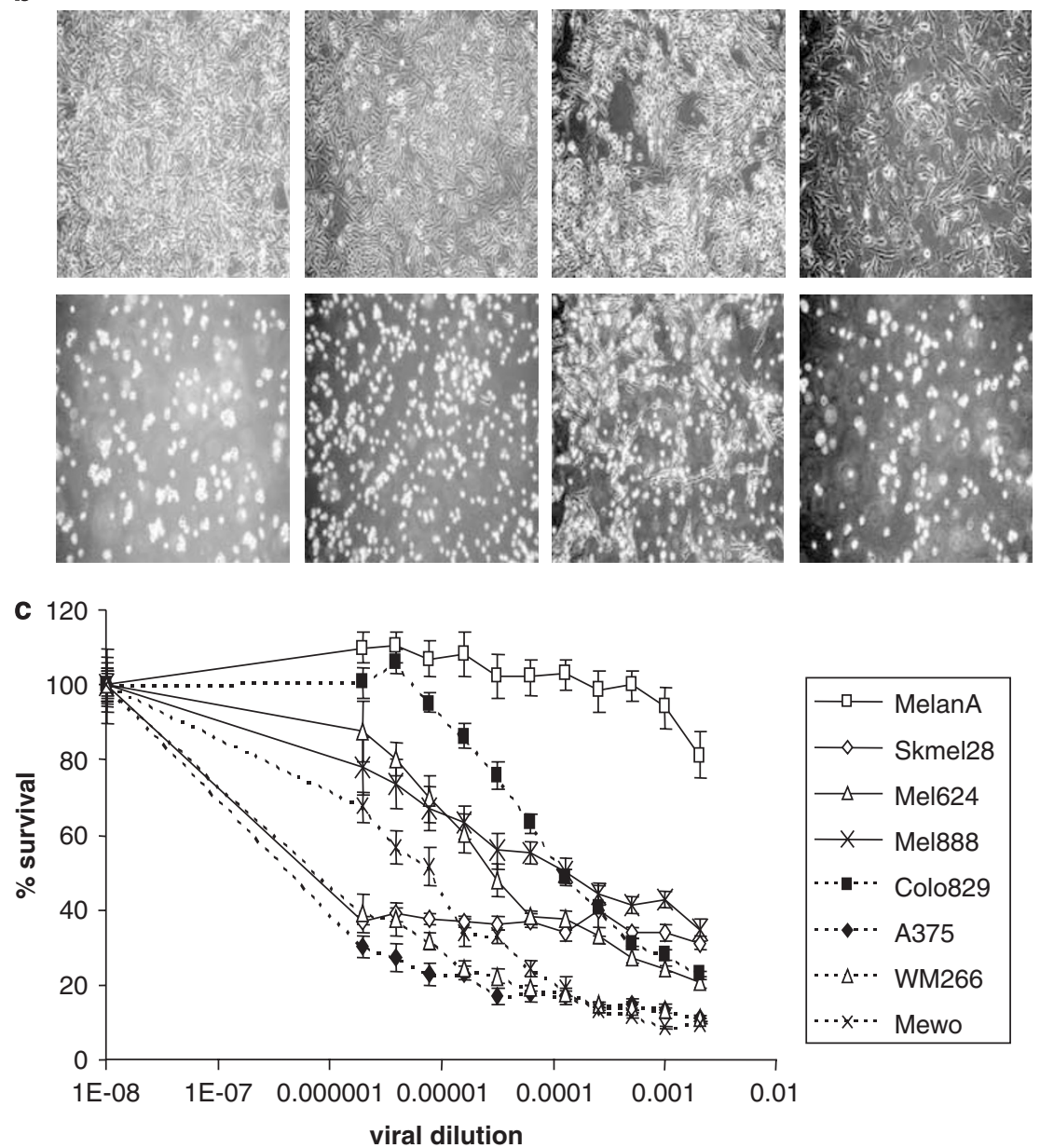

Figure 1 Susceptibility of human melanoma cell lines to reovirus-induced cytotoxicity. (a). Mel-888, Mel-624, Mewo and Skmel-28 cells were either left untreated (control) or treated with $10 \mathrm{PFU} /$ cell reovirus. After 48 or $72 \mathrm{~h}$, all cells were harvested and stained with propidium iodide (PI) before fluorescence-activated cell sorting (FACS) acquisition. Cell death was determined by the proportion of cells staining positive for PI. Average data from four to six independent experiments are shown. Error bars represent s.e.m. (b) Photomicrographs of control (top panel) and $10 \mathrm{PFU} /$ cell reovirus-treated cells (lower panel) were taken $48 \mathrm{~h}$ after reovirus infection. (c) Melan-A, Skmel-28, Mel-624, Mel-888, Colo829, A375, WM266 and Mewo cells were treated with serial dilutions of reoviral stock solution $\left(6.9 \times 10^{8} \mathrm{PFU} / \mathrm{ml}\right)$ and cell survival was determined by 3-(4,5-dimethylthiazol-2-yl)-2,5-diphenyltetrazolium bromide (MTT) assay. Average data from at least three independent experiments are shown. 

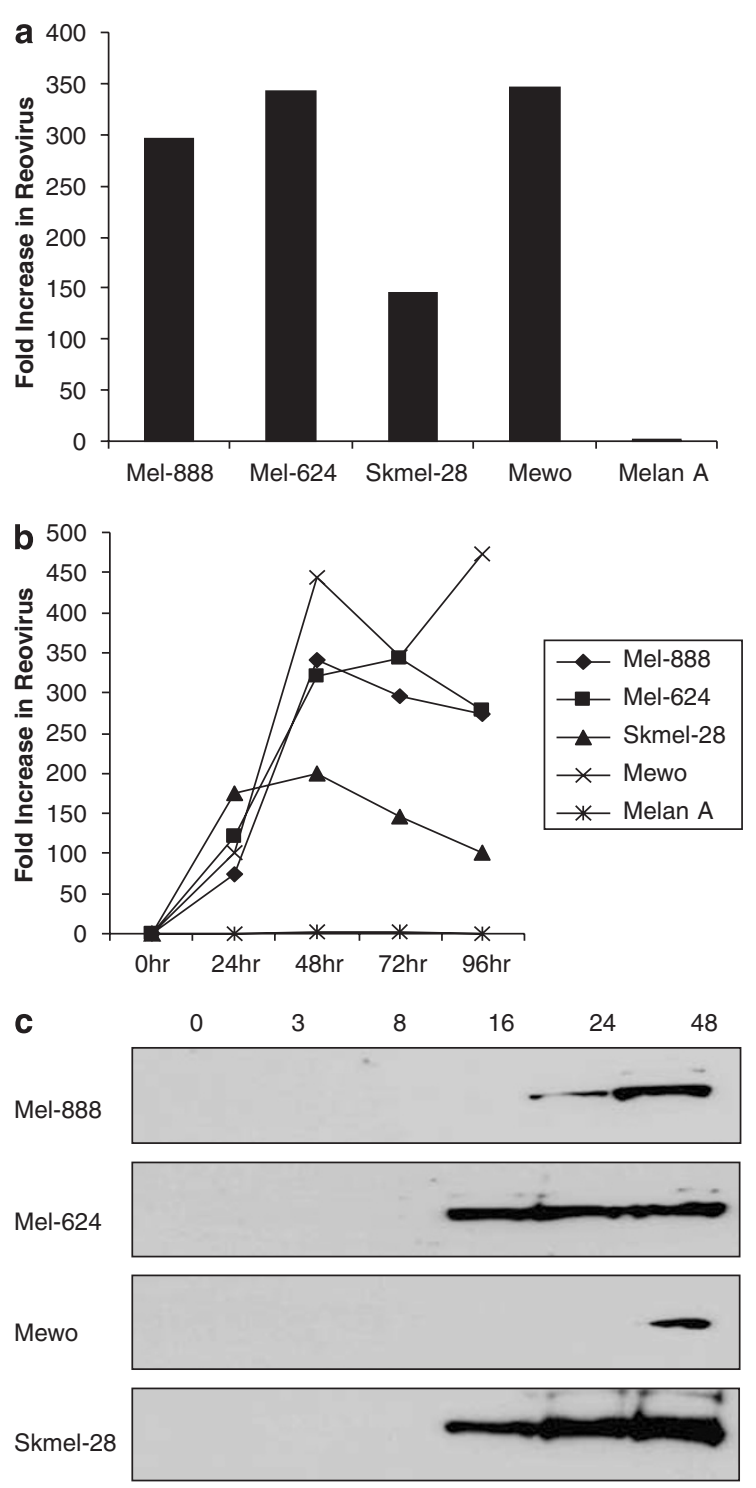

B-Actin

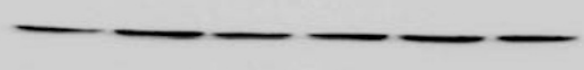

Figure 2 Reovirus growth in human melanoma cell lines. (a) Mel888, Mel-624, Skmel-28, Mewo and Melan-A cells were treated with $10 \mathrm{PFU} /$ cell reovirus for $72 \mathrm{~h}$. Cells and supernatant were harvested, subjected to three rounds of freeze/thaw and the concentration of reovirus determined by plaque assay. The data indicate the fold increase in reovirus compared with input virus and are representative of four independent experiments. (b) To further address the kinetics of viral replication over time, cell lines were treated as in (a), and viral replication determined at 24, 48, 72 and 96 h. (c) Mel-888, Mel-624, Mewo and Skmel-28 cells were either left untreated or treated with $10 \mathrm{PFU} /$ cell reovirus. Whole cell lysates were prepared $0,3,8,16,24$, and $48 \mathrm{~h}$ after infection and proteins were separated using SDS-polyacrylamide gel (SDS-PAGE) electrophoresis. Presence of the $\mu$ outer capsid protein was determined using a polyclonal antireovirus antibody. $\beta$-actin controls demonstrate equal protein loading.

reovirus protein expression can be detected in both transformed and non-transformed cells. Most importantly, the current data shows a clear difference between malignant and normal melanocytes in the most critical functional readouts of tumour cell cytotoxicity and viral replication.

\section{Reovirus treatment for melanoma in vivo}

To examine the therapeutic potential of reovirus in an in vivo preclinical murine model, Mel-888 xenograft tumours were established in athymic nude mice. The tumours were treated with intratumoural injections daily for 5 days of phosphate buffered saline (PBS), UVinactivated or live reovirus once tumours had reached approximately $5 \mathrm{~mm}$ in diameter. Tumour growth was monitored as described in Materials and methods and the survival of mice is shown in Figure 3a. At 70 days, $77 \%$ of mice treated with live reovirus were alive compared with only 25 and $0 \%$ of mice treated with either PBS or UV-inactivated virus, respectively. These differences were statistically significant by the log-rank test (reovirus vs PBS $P=0.011$; reovirus vs UV-inactivated reovirus $P=0.0002$ ). Tumour growth of Mel-888
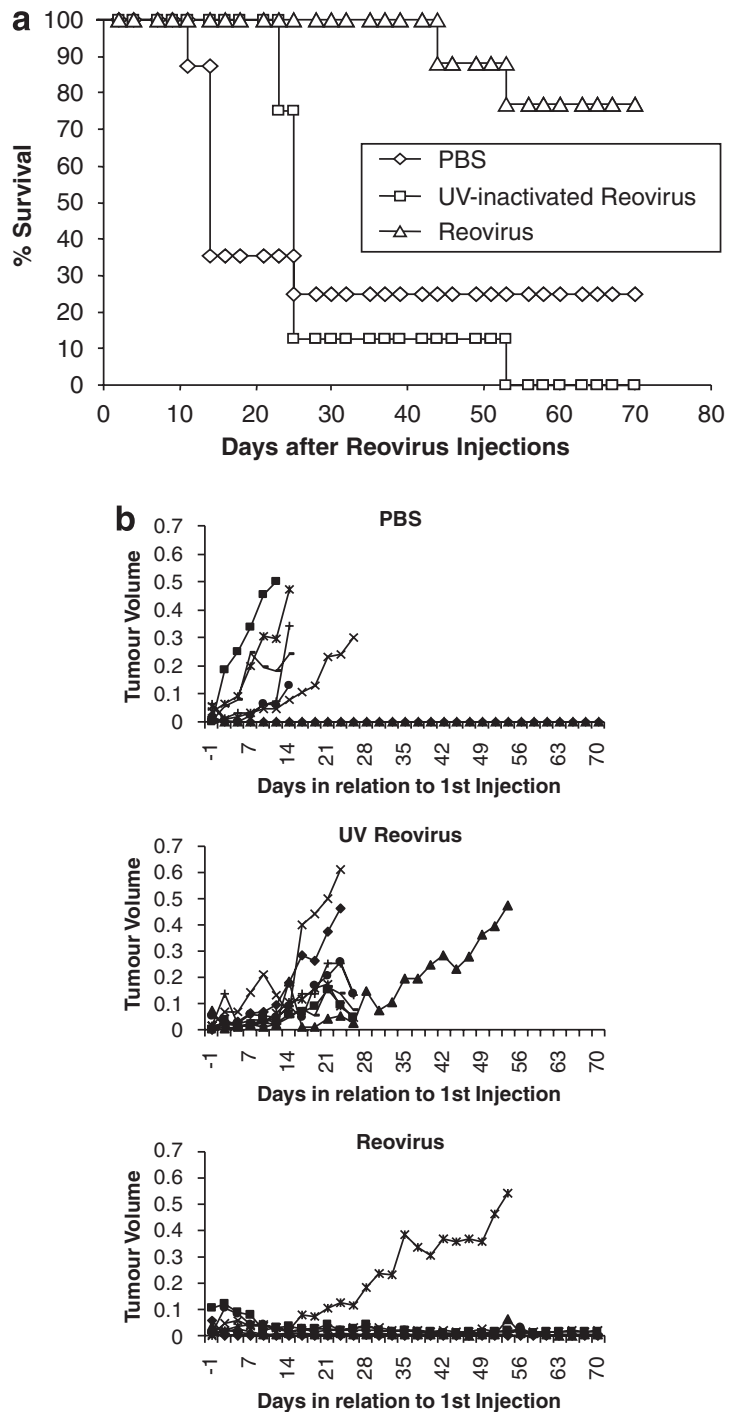

Figure 3 In vivo efficacy of reovirus. Mel-888 xenograft tumours were established in athymic nude mice (eight per group). Tumours were treated with five daily intratumoural injections of either phosphate buffered saline (PBS) or ultraviolet (UV)-inactivated or live reovirus. Tumour growth and survival was monitored up to 70 days after injection. (a) Data represent the percentage of mice surviving over time following injection. (b) Tumour volume of individual mice (each represented by a single line) treated with either PBS or UV-inactivated or live reovirus. 
xenografts is also shown in Figure $3 b$; this shows that Mel-888 tumours progressed in six of eight mice treated with PBS, eight of eight mice treated with UV inactivated reovirus and only one of nine mice treated with live reovirus. The inability of $U V$-inactivated virus to reduce tumour burden in vivo, even though UV-inactivated virus displays some cytotoxicity in vitro, is likely because UV treatment reduces cell killing by three to sixfold in vitro at a PFU of one (data not shown) and, more importantly, UV-inactivated virus is unable to replicate and disseminate through the tumour after injection. No toxicity was seen in any treated animal. These studies confirm that live reovirus can reduce tumour burden and significantly prolong survival after intratumoural delivery to melanoma xenografts.

\section{Role of the Ras signalling pathway in sensitivity to reovirus killing}

In view of the data suggesting that the Ras/RalGEF/p38 pathway is a dominant determinant of reovirus susceptibility, ${ }^{6}$ we evaluated the effect of small molecule inhibitors of the Ras signalling pathway on reovirus effects in SK-Mel28, Mel-624 and Mel-888 cells. All these small molecules showed limited direct toxicity in all three cell lines (data not shown). Hence, reversal of reovirus-mediated toxicity in addition to the inhibitors implicates significant involvement of the specific Ras signalling pathway in viral killing; direct inhibitor toxicity will, if anything, lead to an underestimation of the magnitude of the effect. The p38 MAPK inhibitor SB202190 reduced reovirus-induced cytotoxicity in all three-cell lines, although this was most evident in Mel624 and Mel-888 cells (Figure 4). In contrast, MEK $1 / 2$ inhibition with U0126 or PD184352 (not shown) did not affect cytotoxicity in any of the cell lines tested. The phosphoinositide (PI) 3-kinase inhibitor LY294002 affected cytotoxicity in Mel-624 cells and, to a lesser extent, SK-Mel-28 cells but did not alter the effect of reovirus against Mel-888 cells (Figure 4). Hence, constituents of the Ras/RalGEF/p38 pathway are implicated in reovirus-induced melanoma killing, although there are differential effects in the different cell lines.

\section{Mode of tumour cell death following reovirus infection} Oncolytic viruses can potentially induce tumour cell death through cell lysis secondary to overwhelming replicating viral burden, ${ }^{29}$ through virus-induced apoptosis, ${ }^{7}$ or through a combination of the two. Both lytic (that is, necrotic) and apoptotic cell death have been shown, when associated with induction of appropriate immune 'danger signals', to be capable of priming effective anti-tumour immunity. ${ }^{30}$ To address the mechanism of reovirus-induced cell death in melanoma, tumour lines were treated with $10 \mathrm{PFU} /$ cell reovirus alone or in combination with ZVAD (a pan-caspase inhibitor of apoptosis) and cell viability determined $48 \mathrm{~h}$ post infection. ZVAD alone had no effect, with cell viability remaining comparable to control cells ( $>80 \%$ ). The viability of cells treated with $10 \mathrm{PFU} /$ cell reovirus alone for $48 \mathrm{~h}$ was reduced to $<20 \%$. Strikingly, the addition of ZVAD to reovirus-infected cells significantly reversed viral-induced cytotoxicity in all cell lines tested, suggesting that reovirus induces melanoma cell death
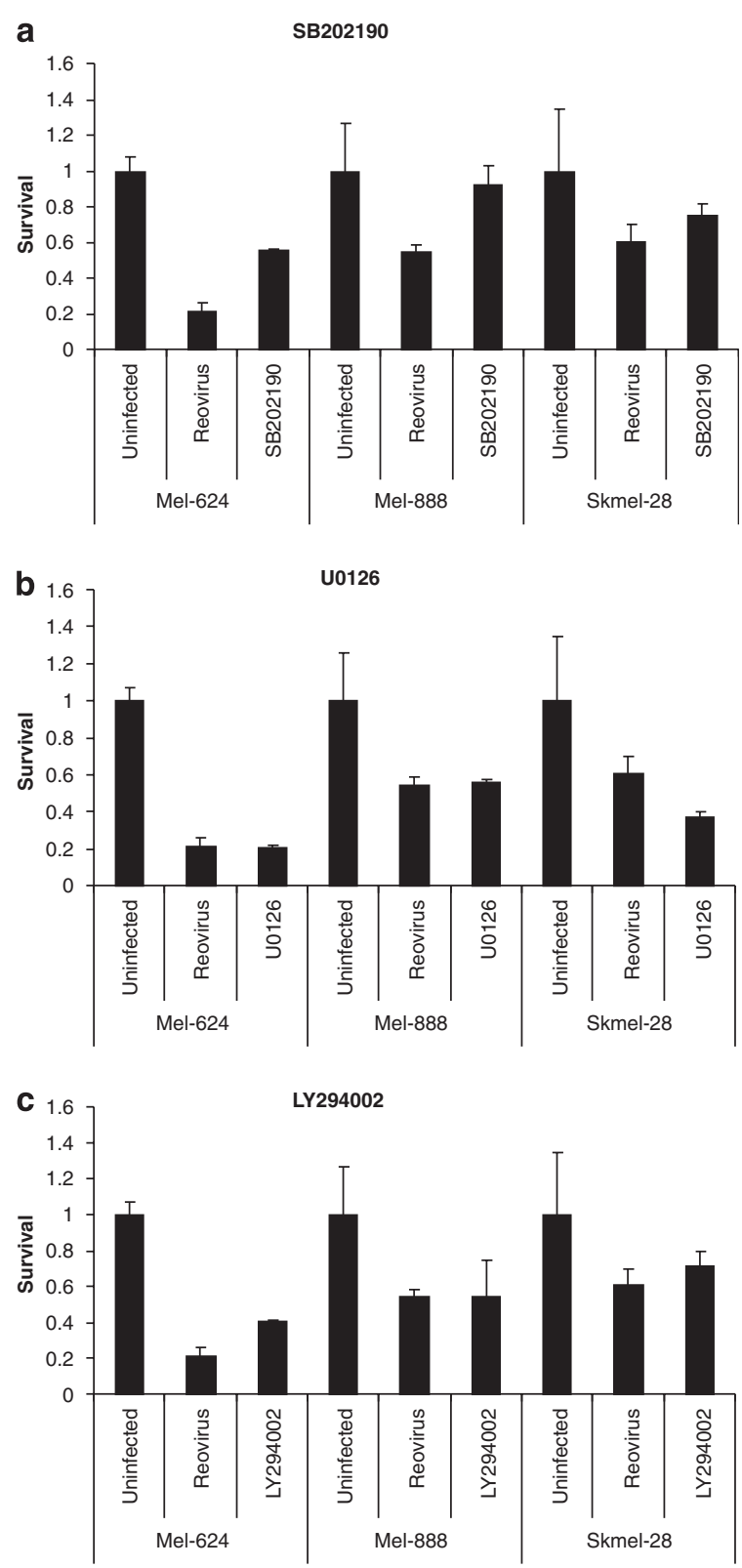

Figure 4 Role of the Ras signalling pathway in reovirus-induced cytotoxicity. Mel-624, Mel-888 and Skmel-28 cells that had been exposed to $10 \mu \mathrm{M}$ SB202190 (a), U0126 (b) or LY294002 (c) were either left untreated or infected with reovirus at a multiplicity of infection (MOI) approximately equal to the $\mathrm{IC}_{50}$. Cell survival was determined by 3-(4,5-dimethylthiazol-2-yl)-2,5-diphenyltetrazolium bromide (MTT) assay at $96 \mathrm{~h}$. Data are representative of at least three independent experiments. Error bars represent s.e.m.

over this time scale predominantly through an apoptotic pathway (Figure 5).

\section{Inflammatory response of tumour cells to reovirus infection}

A further key determinant of the potential immunogenicity of tumour cell death is the pattern of cytokine and chemokine production in the tumour microenvironment, which defines the differentiation, proliferation, recruitment and activation of potential immune effector cells. ${ }^{31}$ Since other oncolytic viruses have been reported to induce an immunogenic death in tumour cells, ${ }^{32}$ we 
considered whether reovirus induces inflammatory mediators in human melanoma. Mel-888, Mel-624, Mewo and Skmel-28 cells were infected with $0.1,1$ and $10 \mathrm{PFU} /$

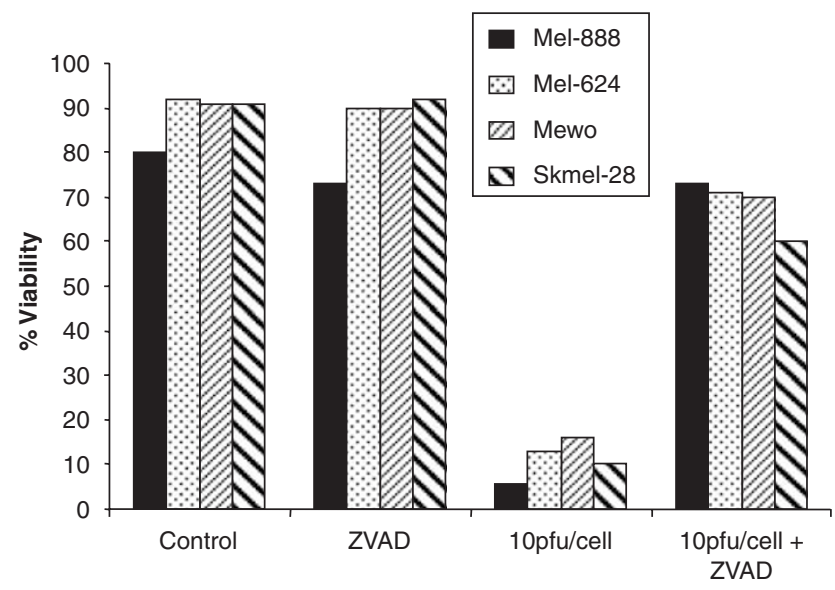

Figure 5 Mechanism of reovirus-induced cytotoxicity. Mel-888, Mel-624, Mewo and Skmel-28 cells were either left untreated (control), treated with $50 \mathrm{mM} \mathrm{ZVAD} \mathrm{or} 10 \mathrm{PFU} /$ cell reovirus alone or pretreated with $50 \mu \mathrm{M} Z \mathrm{ZVAD}$ for $1 \mathrm{~h}$ before the addition of $10 \mathrm{PFU} /$ cell reovirus. Cells were harvested $48 \mathrm{~h}$ after reovirus infection and stained with propidium iodide (PI) before fluorescence-activated cell sorting (FACS) acquisition. Cell death was determined by the proportion of cells staining positive for PI. Data are representative of 2-4 independent experiments.
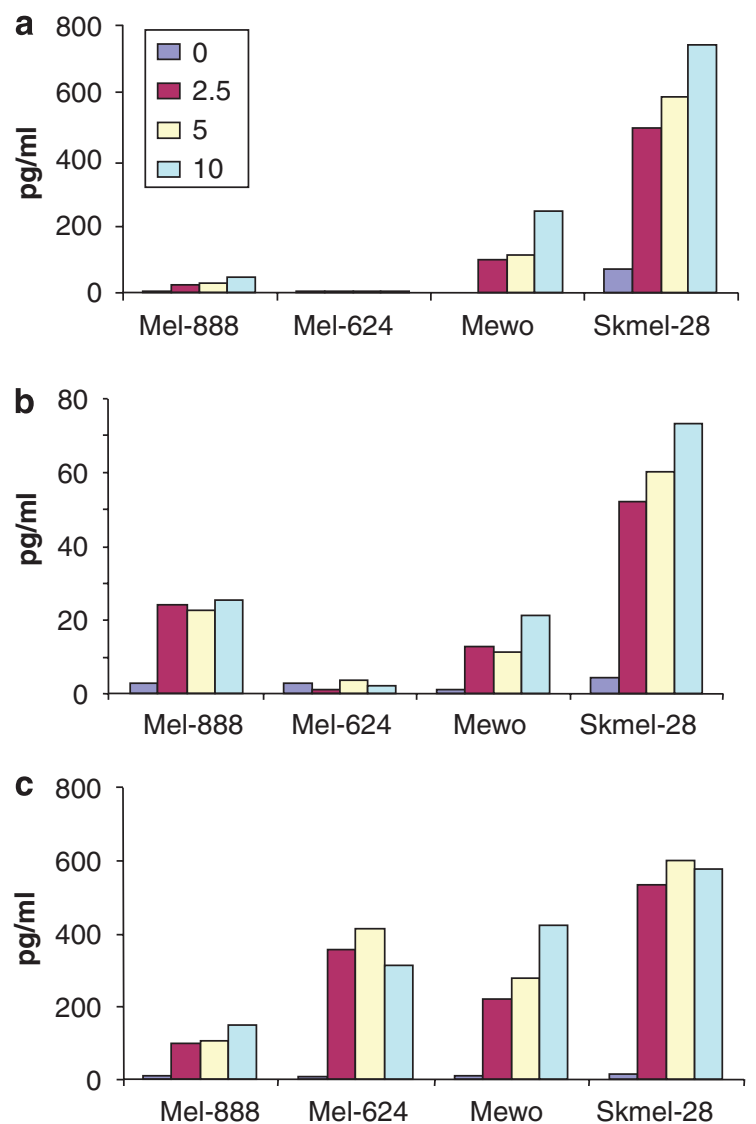

cell reovirus and production of $\operatorname{Mip}-1 \alpha$, Mip1- $\beta$, RANTES, IL-6, IL-8 and IL-10 were determined by ELISA/luminex. Reovirus-induced cytokines and chemokines that are not secreted by uninfected cells, although there were differences between the different melanoma lines (Figures 6a-e). Mel-888, Skmel-28 and Mewo cells secreted Mip- $1 \alpha$, Mip-1 $\beta$, RANTES, and IL-8 in response to reovirus infection, whereas Mel-624 produced only RANTES and IL-8. Mewo were the only cells to produce significant levels of IL-6 in response to the virus (Figure 6e).

Some tumour cells are known to inherently secrete immunosuppressive cytokines such as interleukin (IL)10, which can skew the immune response towards a tolerogenic phenotype, thus potentially contributing to immune evasion by cancers. ${ }^{33,34}$ Interestingly, among these four melanoma lines, significant levels of baseline IL-10 secretion by Mel-888 and Skmel-28 were attenuated by reovirus (Figure 6f). Hence, reovirus not only induces inflammatory cytokine production by infected melanoma cells, but also reduces secretion of immunosuppressive IL-10.

\section{Effects of reovirus on melanoma cells compared with chemotherapy and radiation}

Next, we compared the effects of reovirus infection on melanoma cells with the current standard non-surgical treatment modalities of chemotherapy and radiation.
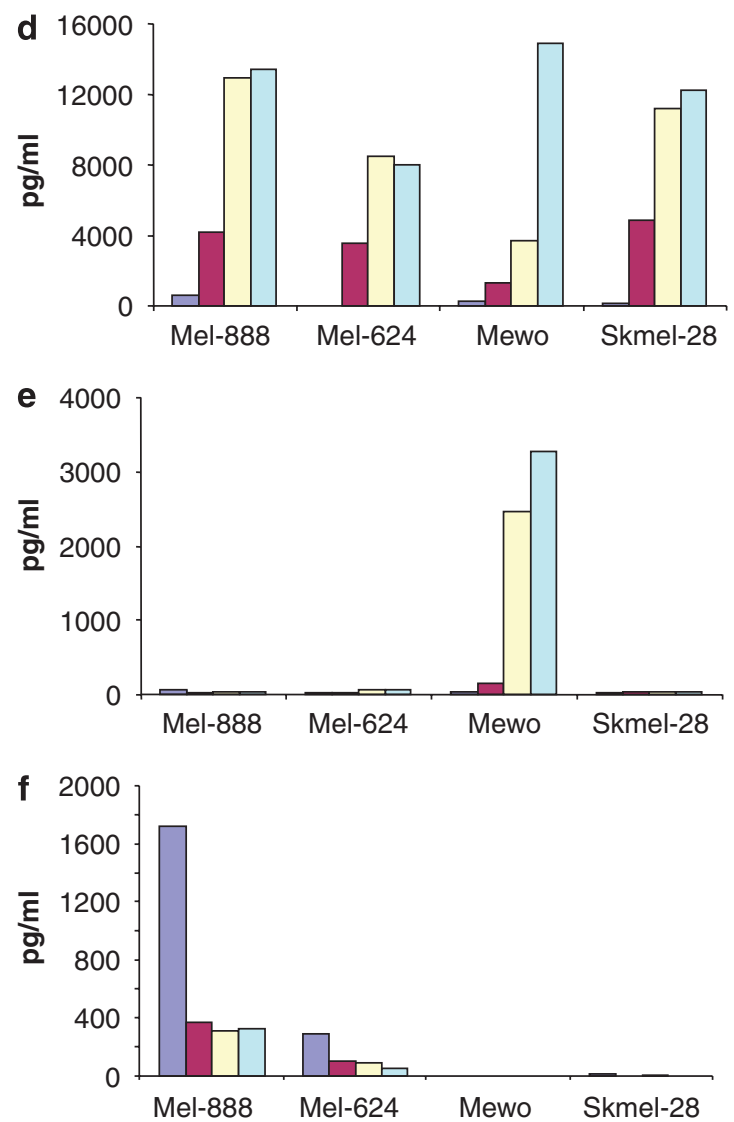

Figure 6 The inflammatory response associated with reovirus infection. Mel-888, Mel-624, Mewo and Skmel-28 cells were either left untreated or treated with 2.5, 5 or $10 \mathrm{PFU} /$ cell reovirus for $48 \mathrm{~h}$. Cell supernatants were harvested and the production of macrophage inflammatory protein (MIP)-1 $\alpha$ (a), MIP-1 $\beta$ (b), RANTES (c), interleukin (IL)-8 (d), IL-6 (e) and IL-10 (f) was determined using ELISA or luminex technology. Data shown are representative of at least two independent experiments. 
Mel-888, Mel-624, Mewo and Skmel-28 cells were treated with $10 \mathrm{PFU} /$ cell reovirus, $1000 \mu \mathrm{g} / \mathrm{ml}$ dacarbazine (DTIC) (a standard chemotherapeutic agent for melanoma), ${ }^{16}$ or $30 \mathrm{~Gy}$ irradiation and cell viability was determined at 48 and $72 \mathrm{~h}$, (Figure 7a). Treatment with $10 \mathrm{PFU} /$ cell reovirus significantly reduced cell viability compared with untreated controls in all cell lines as described previously. On direct comparison, radiation was the least effective agent, having minimal cytotoxic effects at the dose and time points examined, while DTIC induced greater cell kill than irradiation in all cell lines, but remained less cytotoxic than reovirus at all time points. MTT assays were used to confirm the effects of these agents at lower doses and longer time points. These studies confirmed that reovirus was more effective than both DTIC and irradiation at doses as low as 2.5 PFU/ cell and time points out to $144 \mathrm{~h}$ (data not shown). These data suggest that reovirus may be more cytotoxic than conventional therapeutic strategies for melanoma, at least in vitro.

We also compared reovirus and chemotherapy/radiation for induction of inflammatory cytokines. Melanoma lines were treated with various doses of reovirus, DTIC or radiation and levels of IL-8 (as a representative cytokine induced by all cell lines in response to reovirus) were determined at $48 \mathrm{~h}$ (Figure $7 \mathrm{~b}$ ). While a dosedependent increase in IL-8 production was observed in all cell lines following reovirus infection, neither DTIC nor irradiation induced IL-8 in any cell line. IL-6 production by Mewo cells was similarly restricted to treatment with reovirus (Figure 7c). These data suggest that reovirus induces a distinct, potentially immunogenic cell death and is the only treatment modality that may stimulate the production of proinflammatory cytokines within the tumour environment. In separate experiments addressing tumour IL-10 secretion, particularly in response to radiotherapy, we have conversely found an increase in cytokine production on a per cell basis (data not shown), further strengthening a potential role for reovirus as a uniquely immunogenic cytotoxic.

\section{Functional and immunological consequences of inflammatory cytokine production}

Production of inflammatory cytokines can potentially support as well as restrict tumour growth; ${ }^{35}$ therefore the effect of tumour conditioned media (TCM) from reovirus-infected melanoma cells was investigated. Mel-888, Mel-624, Mewo and Skeml-28 cells were either left untreated or treated with $10 \mathrm{PFU} /$ cell reovirus for $48 \mathrm{~h}$ and cell supernatant harvested. This TCM was then added, mixed at a 1:1 ratio with fresh media, to Daudi cells and cell viability determined $120 \mathrm{~h}$ later using PI staining; Daudi cells were used specifically in these studies as they are known to be resistant to reovirus infection/oncolysis, ${ }^{13}$ ruling out any direct cytotoxic effects of the virus. Figure $8 \mathrm{a}$ demonstrates that untreated Daudi cells and those treated directly with $20 \mathrm{PFU} /$ cell live reovirus, or supernatant from noninfected melanoma cells, remained mainly viable with only $30 \%$ of cells staining positive for PI. In contrast, Daudi cells treated with cell supernatant from virally infected cells were killed, with the percentage of PIpositive cells increasing to $>80 \%$. These results show that soluble factors produced in response to viral infection reduce tumour viability in bystander cells, thereby providing an additional mechanism by which reovirus may exert its cytotoxic effects.

To begin to address the immunological consequences of inflammatory cytokine production by reovirus-infected tumour cells, Mel-888, Mel-624, Mewo and SKmel28 cells were infected with 10 PFU/cell reovirus for $48 \mathrm{~h}$ and cell supernatants harvested. Reovirus was removed from these supernatants by filtration to exclude any direct viral effects. TCM was then added for $24 \mathrm{~h}$ to monocte-derived human myeloid dendritic cells (DC), as key determinants of the immune activation or tolerance instigated by tumours, ${ }^{36}$ and their level of activation monitored by phenotypic maturation. Expression of CD80 and CD86 (as representative activation markers) on immature DC, LPS-treated DC (as a positive control) or DC treated with TCM from either non-infected or reovirus-infected melanoma cells is shown in Figure $8 \mathrm{~b}$. While TCM from uninfected cells had almost no effect on CD80/86, both activation markers were unregulated in response to reovirus-infected melanoma cells. This data suggests that the inflammatory environment generated by reovirus-infection of melanoma cells is capable of activating human myeloid DC for potential generation of anti-tumour immunity.

\section{Response of primary melanoma cells to reovirus}

Since immortal, established cell lines may be a poor representation of clinical disease, we also tested reovirus on melanoma cells freshly isolated from patients. Single cell suspensions of melanoma were derived from resected tumour tissue as described in Materials and methods and adherent cell populations cultured. To confirm that these cells were melanoma in origin (rather than fibroblast or other cell contaminants), the expression of MART-1, a defined melanoma tumour-associated antigen, ${ }^{37}$ was examined. Data is shown for tumour cell isolates from two independent donors (MT/05/129 and MT/05/131); the majority of cells stained positive for MART-1 expression, confirming successful isolation of primary melanoma cells (Figure 9a).

To determine the sensitivity of primary melanoma to reovirus infection and oncolysis, MT/05/129 and MT/ 05/131 cells were treated with $10 \mathrm{PFU} /$ cell and cell viability was examined 24,48 and $72 \mathrm{~h}$ post infection (Figure 9b). Although no cytotoxicity was seen at $24 \mathrm{~h}$ post infection, cell viability was reduced at 48 and $72 \mathrm{~h}$ in both donors. Hence, reovirus was an effective cytotoxic agent against primary melanoma, although primary cells were less sensitive than highly proliferative established cell lines.

The extent of viral replication in these cells was also determined. MT/05/129 and MT/05/131 cells were infected with $10 \mathrm{PFU} /$ cell reovirus for $72 \mathrm{~h}$ and levels of virus in cells/supernatant quantified by plaque assay. For the two donors, there was a 10- to 40-fold increase in reovirus titre over input virus confirming that viral replication occurred in both primary samples (Figure 9c); as with cytotoxicity, the levels of replication were significantly lower in primary tumour cells than in the melanoma cell lines (Figure 2a). We also analysed proinflammatory cytokine production by MT/05/129 and MT/05/131 cells $48 \mathrm{~h}$ following treatment with $10 \mathrm{PFU} /$ cell reovirus (Figure 9d). The virus again stimulated the production of Mip- $1 \alpha$, Mip-1 $\beta$, RANTES 
and IL-6 in both donors. Although IL-8 responses were less clear-cut due to significant baseline secretion by both donors, a small increase was also seen over the time course of the experiment. Hence, the inflammatory response of tumour cell lines in response to reovirus is also seen on infection of primary melanoma cells.

a
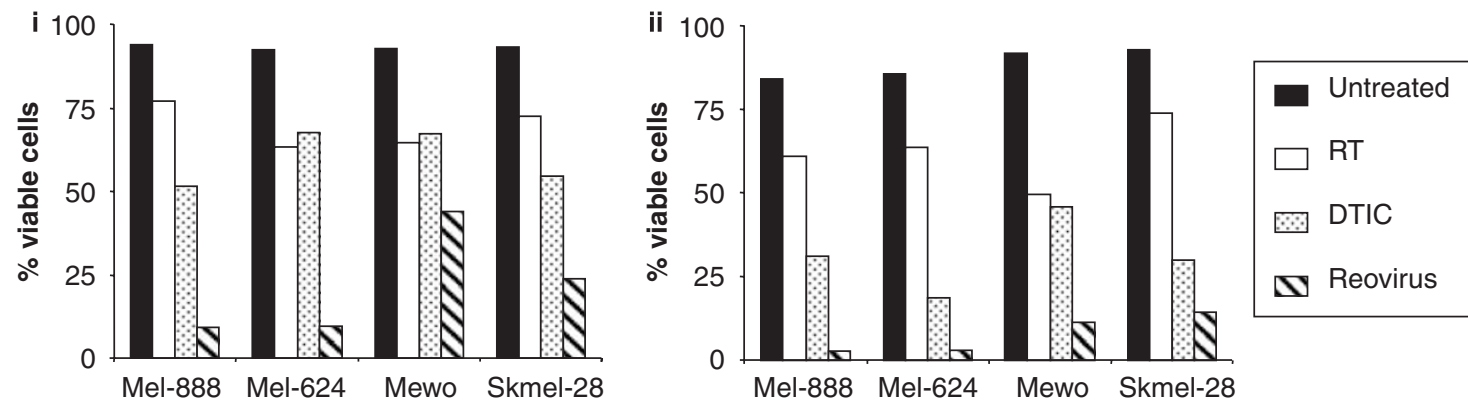

b
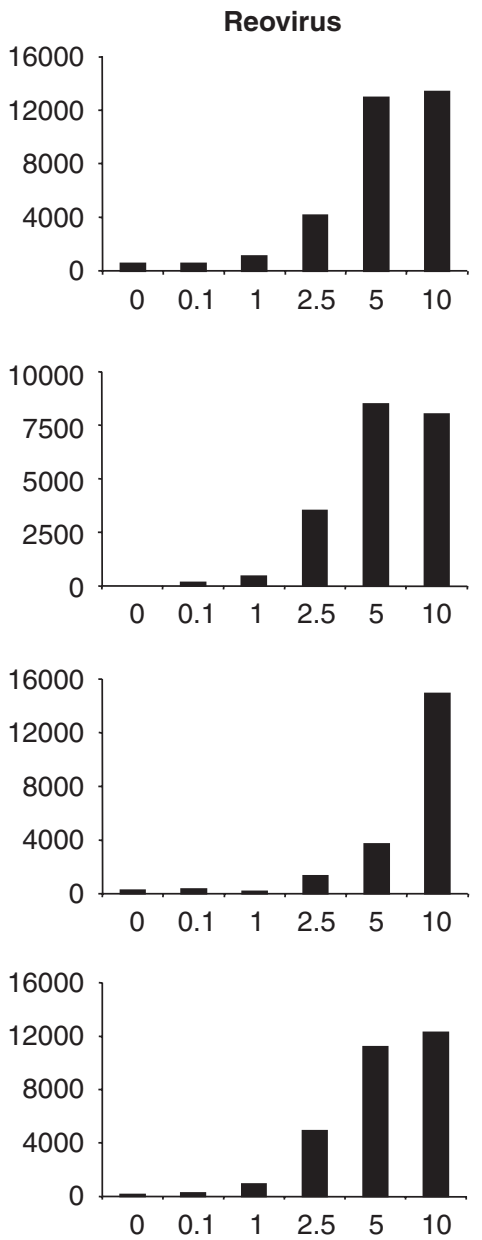

C

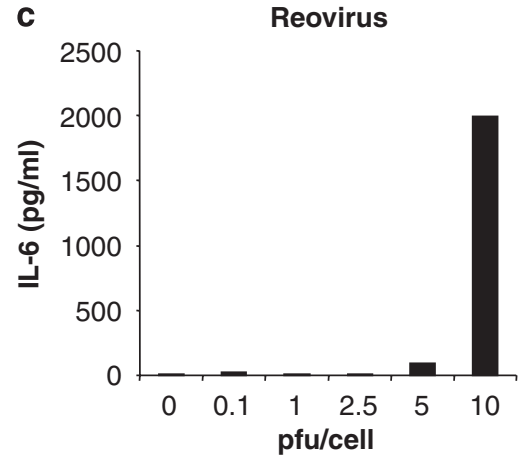

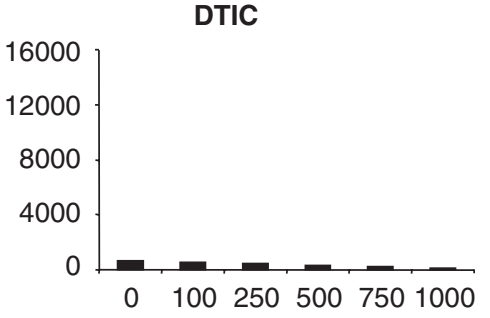
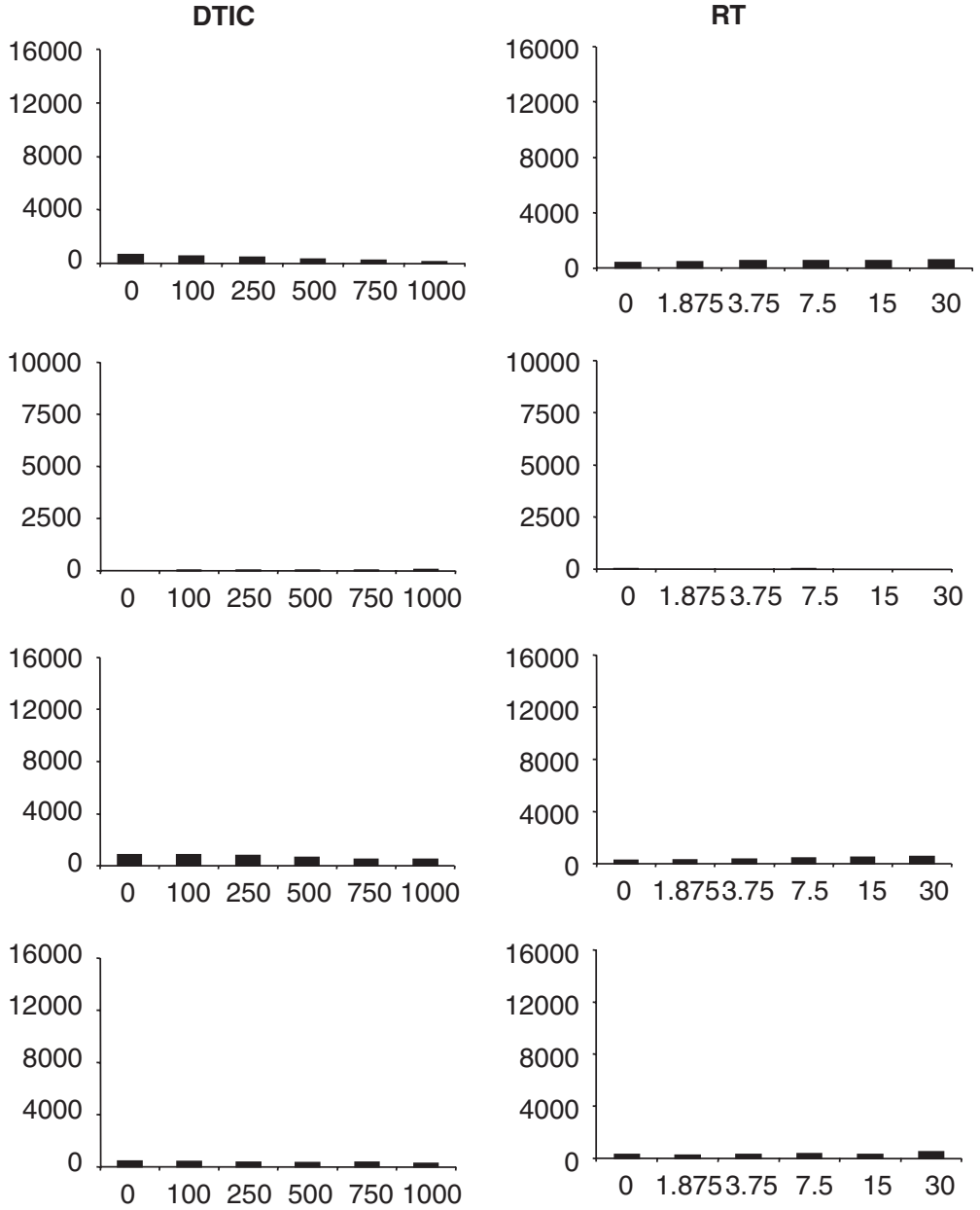

DTIC

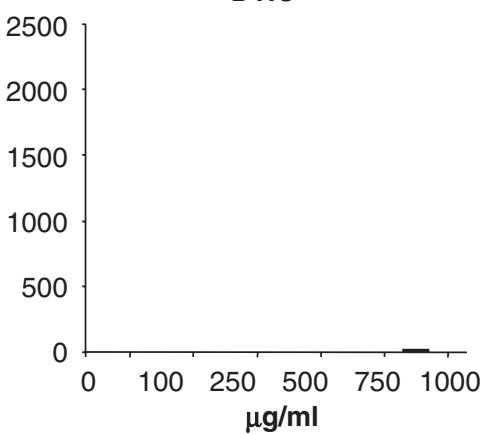

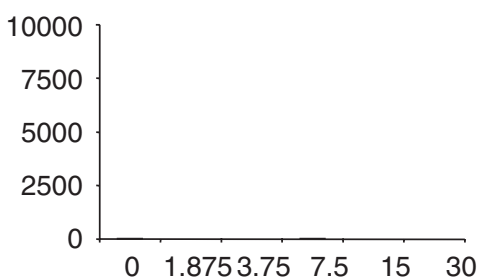
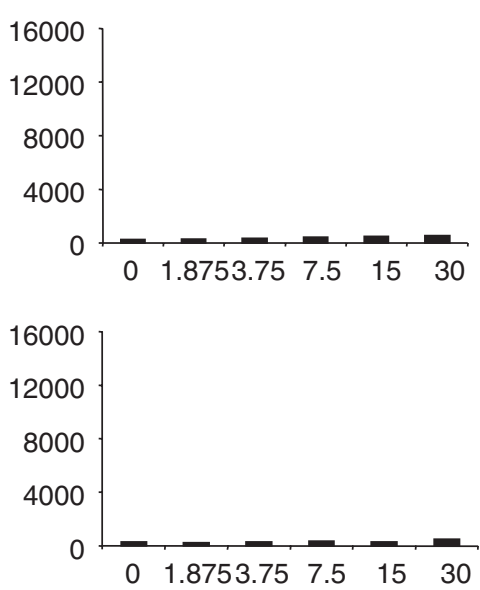

Radiation

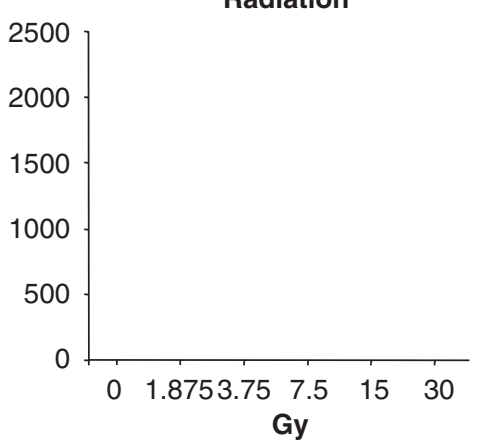




\section{Discussion}

Vertical growth phase malignant melanoma is an extremely aggressive tumour that frequently metastasizes to disseminated sites. $^{38}$ Metastatic malignant melanoma (MMM) is incurable with standard surgery, radiotherapy or cytotoxic chemotherapy. Response rates to standard cytotoxic agents, such as DTIC, temozolomide and cisplatin, are low $(<20 \%)$ and usually of short duration. ${ }^{16}$ As MMM frequently expresses tumourassociated antigens, it has been seen as a suitable candidate for the development and testing of immunotherapies. $^{39}$ Indeed, a number of agents including interferon- $\alpha$, interferon- $\gamma$, IL- 2 , specific monoclonal antibodies (e.g. anti-CTLA4) and antimelanoma vaccines have been evaluated against MMM. ${ }^{40}$ In most of these trials, there have been some patients who have responded to the test agent. Furthermore, preclinical and clinical responses have been shown to correlate with the occurrence of vitiligo, which involves an autoimmune response against normal melanocytes. ${ }^{41}$ Indeed, the deliberate establishment of an autoimmune response against normal melanocytes has been proposed as a potential approach for promoting antimelanoma immunity. ${ }^{42,43}$ Therefore, therapies that provoke immune activation in addition to direct tumour-specific cytotoxicity represent rational approaches to the treatment of MMM.

In the studies reported here, we have demonstrated that reovirus is capable of replicating in and killing a range of human melanoma tumour cell lines. Significantly, normal Melan-A melanocytes were resistant to reovirus-mediated cytotoxicity and did not support viral replication (Figures 1, 2). The antimelanoma effect of reovirus was also apparent in a xenograft model (Figure 3). Therefore, these data alone support the potential value of reovirus as a direct therapeutic for MMM.

Our finding that reovirus-induced melanoma cell death is caspase-dependent (Figure 5) at the same time as supporting efficient viral replication (Figure $2 b$ ), is consistent with a growing body of evidence describing the signalling cascades triggered by reovirus infection, and the complexity of the multiple downstream cell pathways they activate, which control cell fate as well as potential viral replication..$^{8,9,44}$ The detailed relationship between the cell's Ras status and the various consequences of infection has not been fully elucidated yet. ${ }^{5,44}$ While our data suggests components of the Ras/ RalGEF/p38 pathway ${ }^{6}$ (particularly p38 and in some cell lines PI3K, but not MEK 1/2) are implicated in the reovirus-induced killing of melanoma (Figure 4), for clinical application the key findings of this study are the sensitivity of melanoma (both cell lines and primary tumours) to reovirus killing and replication, together with the relative resistance of Melan-A normal melanocytes. Sequencing to date of our lines has shown that they are all mutant in the Ras/BRAF pathway (as expected for melanomas ${ }^{45}$ ), while Melan-A is normal. Reovirus was also significantly more toxic, at least in vitro, than the current non-surgical treatment modalities of chemotherapy and radiotherapy (Figure 7).

As well as describing, for the first time, the in vitro and in vivo potential of reovirus for the treatment of human melanoma, this study addresses some immunological consequences of reovirus-induced human tumour cell killing. Despite intensive investigation of the direct cytotoxic ability of oncolytic viruses, relatively little attention has been paid to their potential to induce antitumour immunity, despite the fact that virus-induced cell death should create an inflammatory, immunologically 'dangerous' environment, with proinflammatory cytokine release, the presence of toll-like receptor ligands and infiltration of cells of the innate immune system. ${ }^{46-48}$ In fact, a role for anti-tumour immunity has been implicated in combination treatment with reovirus plus chemotherapy, although the cellular mechanisms responsible were not defined. ${ }^{49,50}$ Although the immune response to oncolytic viruses will include antiviral as well as anti-tumour priming, which may restrict rather than promote tumour regression, there is a clear body of evidence that concomitant immune priming against TAA can contribute significantly to viral therapy. ${ }^{17-20}$ Much of this data is from animal models rather than human tumours and none has explored reovirus-induced antitumour immune priming as yet.

Here, we show that reovirus induces killing of melanoma cells that is associated with the release of a range of inflammatory cytokines/chemokines (as well as abrogation of immunosuppressive IL-10), which is quite distinct from death following chemotherapy or radiotherapy (Figures 6 and 7). We investigated the ability of reovirus to stimulate the production of $\mathrm{Mip}-1 \alpha / \beta$, RANTES, IL-8 and IL-6, which play an active role in immune cell recruitment and activation. IL-8, RANTES and Mip $-1 \alpha / \beta$ can recruit a range of immune effector cells including monocytes, dendritic cells, neutrophils and lymphocytes; ${ }^{51}$ IL-6 can inhibit the immunosuppressive function of regulatory T cells; ${ }^{52}$ RANTES can activate both $\mathrm{T}$ cells and natural killer cells and facilitate priming of antigen-specific $\mathrm{T}$ cells by acting in concert with costimulatory signals. ${ }^{53}$ Hence, the current data (Figures $6,7 \mathrm{~b}, \mathrm{c}$ and $9 \mathrm{~d}$ ) demonstrates for the first time that reovirus-induced melanoma death stimulates the production of proinflammatory cytokines/chemokines, while reducing the production of IL-10 (Figure 6f). This suggests that reovirus-induced cell killing may reverse the immunosuppressive nature of the tumour environment, facilitate active recruitment of immune effector cells and thereby aid the generation of innate and adaptive anti-tumour immune responses.

To further investigate the functional consequences of inflammatory cytokine production from reovirus

Figure 7 Reovirus-induced cytotoxicity and proinflammatory response compared with chemotherapy and irradiation. (a) Mel-888, Mel-624 Mewo and Skmel-28 cells were either left untreated or treated with 30 Gy irradiation, $1000 \mu \mathrm{g} / \mathrm{ml}$ dacarbazine (DTIC) or 10 PFU/cell reovirus. Cells were harvested 48 (i) or $72 \mathrm{~h}$ (ii) after treatment and stained with propidium iodide (PI) before fluorescence-activated cell sorting (FACS) acquisition. Cell death was determined as the proportion of cells staining positive for PI. (b) Melanoma cell lines were either left untreated, treated with $0.1,1,2.5,5$ or $10 \mathrm{PFU} /$ cell reovirus, $100,250,500,750,1000 \mu \mathrm{g} / \mathrm{ml}$ DTIC or $1.875,3.75,7.5,15$ or $30 \mathrm{~Gy}$ irradiation. $48 \mathrm{~h}$ after treatment, supernatants were harvested and the production of interleukin (IL)-8 was determined by ELISA. (c) Mewo cells were treated as in (b) and the production of IL-6 was determined by ELISA. Data shown are representative of at least two independent experiments. 
infected melanoma cells, we further determined the effect of this cytokine production on tumour cell growth, as it has previously been reported that cytokines such as IL-6 and IL-8 can promote rather than restrict tumour progression. ${ }^{54,55}$ Figure 8 a clearly demonstrates that TCM from infected cells, containing a range of inflammatory cytokines, was directly cytotoxic against reovirus-resistant Daudi cells. Further characterization
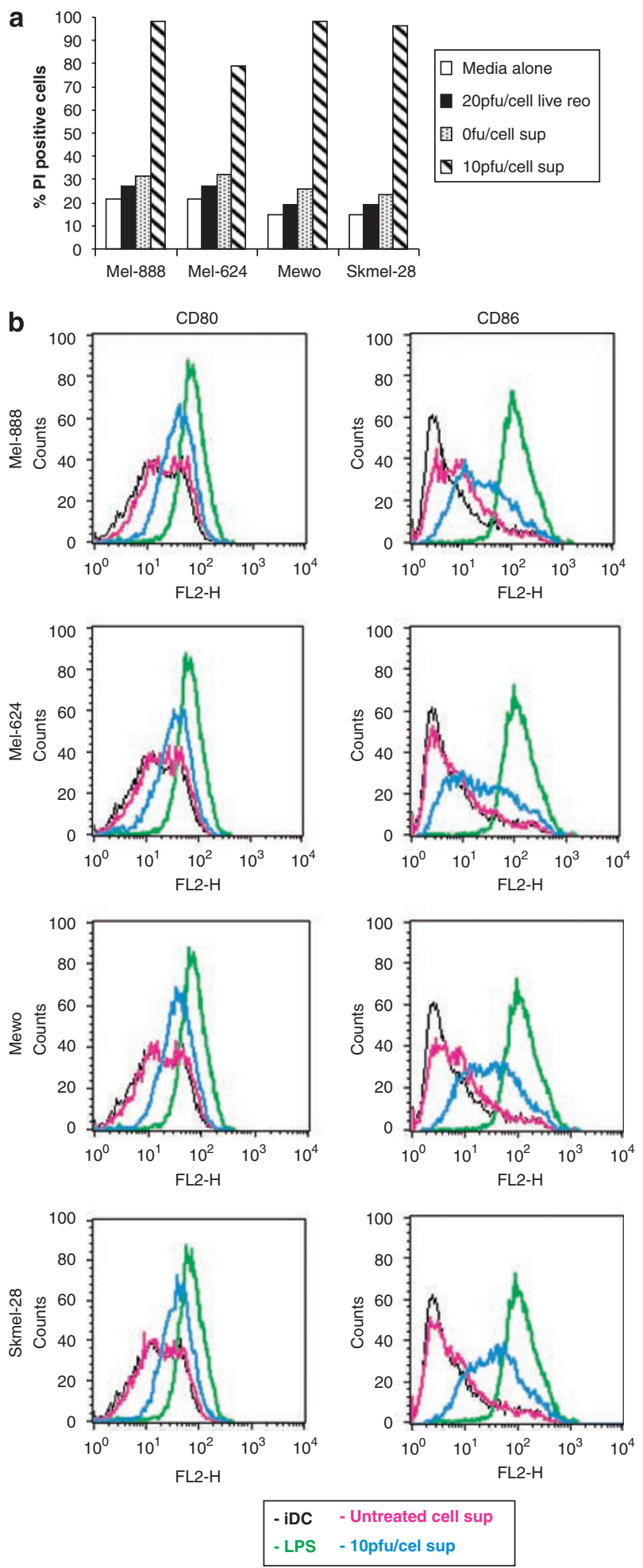

of the factors responsible for this anti-tumour effect is currently underway.

As a first step towards addressing the potential immunological consequences of reovirus-induced cytokine production by melanoma cells, TCM from reovirusinfected cells was added to human myeloid DC, a pivotal antigen presenting cell essential for priming anti-tumour immune responses. ${ }^{36}$ DC underwent phenotypic activation on culture with TCM from reovirus-infected, but not uninfected melanoma cells, showing that soluble factors secreted by infected tumour cells can activate key immune effector cells, potentially facilitating priming of anti-tumour immunity. In support of this hypothesis, preliminary studies from our laboratory have shown (i) that reovirus-infected human tumour cells are a more effective source of TAA than uninfected cells, when loading DC for naïve anti-tumour cytotoxic T cell (CTL) priming in vitro and (ii) that a reovirus-resistant tumour cell line can nevertheless be effectively treated in vivo in an immunocompetent mouse model following intratumoural injection, through a CD8 and natural killerdependent mechanism.

The balance between antiviral and anti-tumour immune priming with oncolytic viral therapy is likely to depend significantly on route of administration; intravenous therapy is associated with a rapid antibody response, careful abrogation of which can support viral persistence and enhance therapy, ${ }^{22}$ while direct or regional administration, which more effectively restricts cellular interactions to the otherwise suppressive intratumoural immune milieu, may be particularly effective at breaking tolerance to TAA. Comparative studies in immunocompetent models, and more importantly detailed analysis of treated patients for immune reactivity against viral antigens and TAA, will shed further light on these issues.

In summary, reovirus represents a promising agent for the treatment of human melanoma. The virus killed, and replicated in, freshly resected melanoma as well as immortal cell lines, and was effective therapy following intratumoural injection in a xenograft model. Reovirus killing of melanoma cells was consistently dependent on p38 MAPK, was more potent in vitro than chemotherapy or radiation, and comprised a distinct caspase-dependent, inflammatory cell death, which has the potential to support additional bystander anti-tumour effects through cytokine-induced tumour cytotoxicity and activation of key immune effector cells and immune priming.

Figure 8 Functional consequences of reovirus-induced inflammatory cytokine production. (a) Mel-888, Mel-624, Mewo and Skmel-28 cells were either left untreated or treated with $10 \mathrm{PFU} /$ cell reovirus for $48 \mathrm{~h}$. Tumour conditioned media (TCM) was harvested and added mixed at a 1:1 ratio with fresh media to reovirus resistant Daudi cells. After $120 \mathrm{~h}$, viability of Daudi cells was examined by propidium iodide (PI) staining. Data shown are representative of at least three independent experiments. (b) Human immature myeloid dendritic cells (iDC) were left untreated, treated with lipopolysaccharide (LPS) or cultured in tumour conditioned media (TCM) from Mel-888, Mel-624, Mewo and Skmel-28 cells grown $\pm 10 \mathrm{PFU} /$ cell reovirus for the previous $48 \mathrm{~h}$ and expression of CD80 and CD86 determined by flow cytometry. Data shown are representative of three independent experiments. 
a

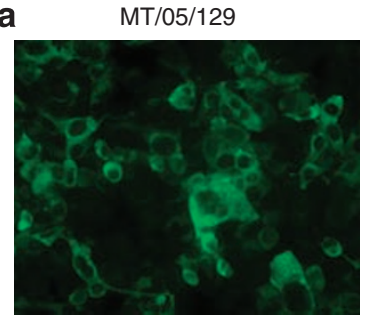

C

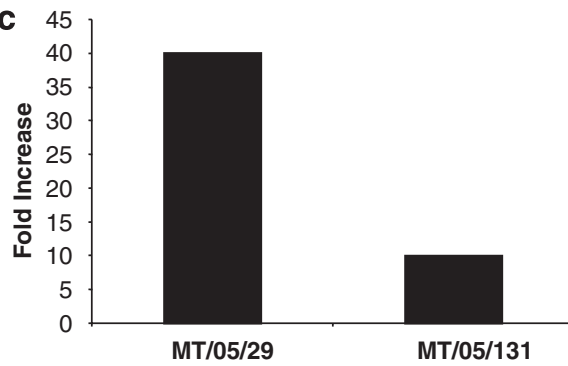

d

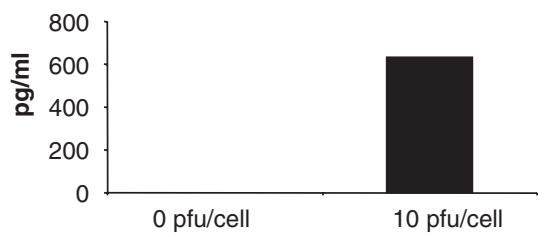

Mip1 $\beta$

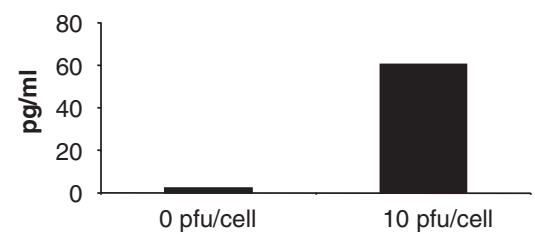

Rantes
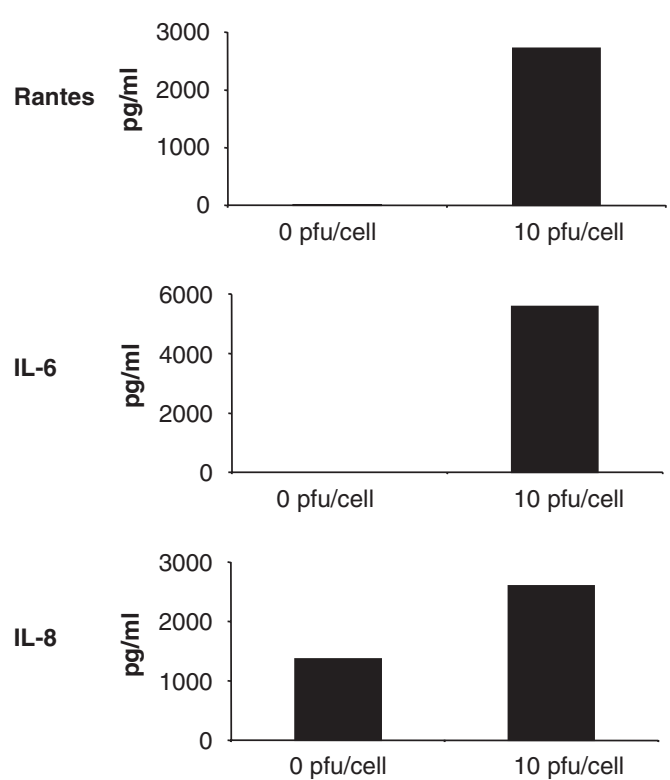

b

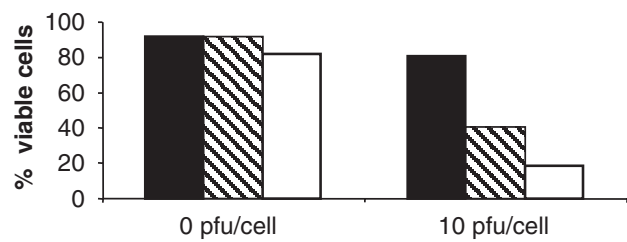

MT/05/131
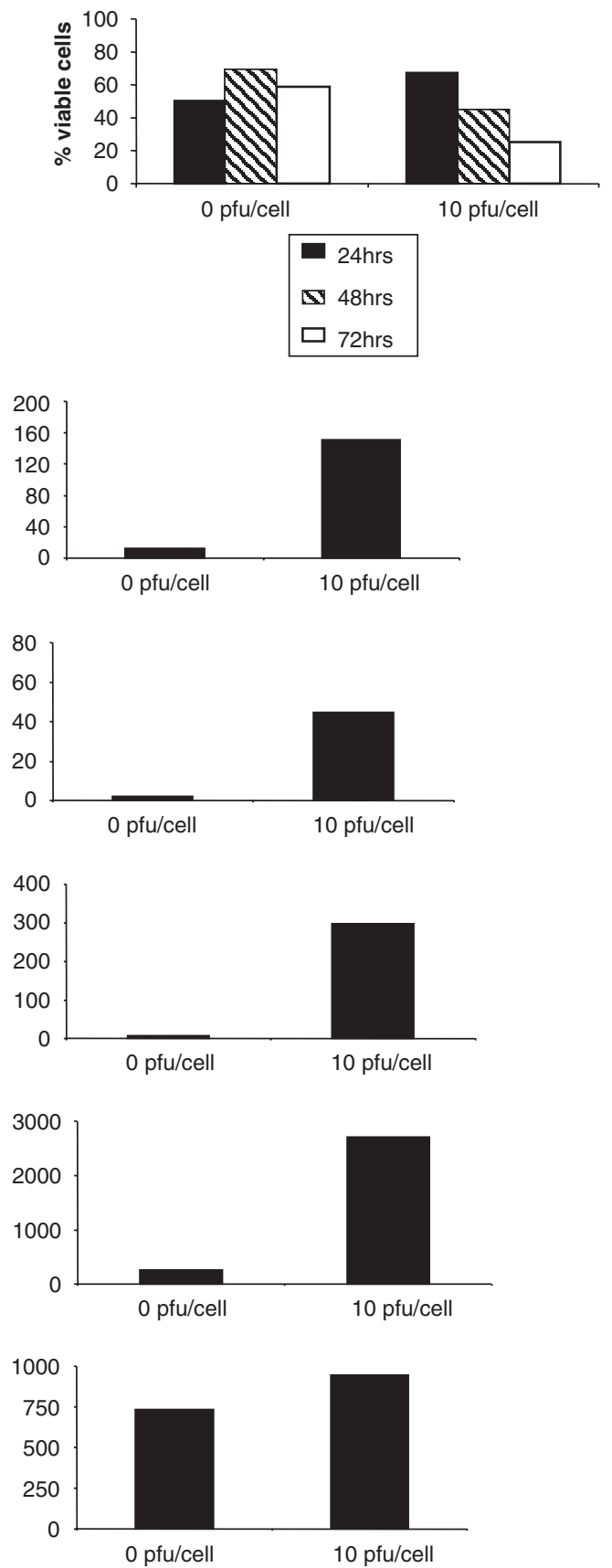

Figure 9 Response of primary melanoma cells to reovirus. Primary melanoma cells (MT/05/129 and MT/05/131) were isolated as described in Materials and methods. (a) Expression of MART-1 in MT/05/129 and MT/05/131 cells was examined using immunofluorescence. (b) MT/05/129 and MT/05/131 cells were either left untreated or treated with 10 PFU/cell reovirus for 24,48 or $72 \mathrm{~h}$. Cells were harvested and stained with propidium iodide (PI) before fluorescence-activated cell sorting (FACS) acquisition. (c) MT/05/ 129 and MT/05/131 cells were treated with $10 \mathrm{PFU} /$ cell reovirus for $72 \mathrm{~h}$. Cells and supernatant were harvested, subjected to three rounds freeze/thaw and the concentration of reovirus was determined by plaque assay. Data shown represent the fold increase in reovirus compared to input virus and are representative of three independent experiments. (d) Cell supernatants were harvested from control- or reovirustreated MT/05/129 and MT/05/131 cells $48 \mathrm{~h}$ after infection. Concentrations of MIP-1 $\alpha$, MIP-1 $\beta$, RANTES, interleukin (IL)- 6 and IL- 8 were determined using luminex technology. Data shown are representative of three independent experiments. 


\section{Materials and methods}

Cell culture

SKmel-28, Mel-624, Mel-888, Colo829, A375, WM266, Mewo and Daudi cells were grown in Dulbecco's Modified Eagle's Medium (DMEM) (Gibco BRL, Paisley, UK) supplemented with $10 \%(\mathrm{v} / \mathrm{v})$ foetal calf serum (FCS) (Harlan Sera-Labs, Crawley Down, UK) and 1\% (v/v) L-glutamine (Gibco BRL). Melan-A, a murine normal melanocyte cell line, ${ }^{24}$ was grown in Roswell Park Memorial Institute medium (Gibco BRL) supplemented with $10 \%$ (v/v) FCS, $200 \mathrm{nM}$ phorbol 12myristate 13-acetate (TPA) (Sigma Aldrich Co. Ltd, Gillingham, UK) and $130 \mathrm{pM}$ cholera toxin (Sigma Aldrich). Human myeloid immature DCs were generated from human peripheral blood mononuclear cells using monocyte adherence as previously described. ${ }^{56}$ All cell lines were grown at $37^{\circ} \mathrm{C}$ in a humidified atmosphere containing $5 \% \mathrm{CO}_{2}$ and were routinely tested for, and confirmed free of, mycoplasma.

\section{Reovirus, DTIC and irradiation}

Reovirus type 3 Dearing stain was provided by Oncolytics Biotech Inc. (Calgary, Canada). Virus titre was determined by a standard plaque assay using L929 cells (Cancer Research UK, London, UK). Stocks at $3.45 \times 10^{10}$ $\mathrm{TCID}_{50} / \mathrm{ml}$ were stored in the dark at neat and 1:50 concentrations in PBS at $-80{ }^{\circ} \mathrm{C}$; where indicated cells were irradiated to $30 \mathrm{~Gy}$ at $2.7 \mathrm{~Gy} \mathrm{~min}^{-1}$ (GammaCell Elite $1000{ }^{137} \mathrm{Cs}$ source) or treated with $1000 \mu \mathrm{g} / \mathrm{ml}$ dacarbazine (DTIC).

\section{Ras pathway inhibitors}

Small molecule inhibitors of components of the Ras signalling pathway were used to test their effect on reovirus-mediated cytotoxicity. MEK1/2 inhibitor U0126 (1,4-Diamino-2,3-dicyano-1,4-bis(2-aminophenylthio) butadiene), PI3K inhibitor LY294002 (2-(4-morpholinyl)8-phenyl-4H-1-benzopyran-4-one) and p38 MAPK inhibitor SB202190 (4-(4-fluorophenyl)-2-(4-hydroxyphenyl)5-(4-pyridyl)1H-imidazole) were all obtained from Merck Biosciences, UK. All agents were stored at $-20{ }^{\circ} \mathrm{C}$ as $10 \mathrm{~mm}$ stock solutions in dimethyl sulphoxide, except LY294002, which was stored in ethanol until use.

\section{Measurement of cell viability by propidium iodide staining}

Melanoma cells or Daudi cells were seeded at a known density and either infected with different concentrations of reovirus or treated with TCM from non-infected or reovirus-infected melanoma cells (10 PFU/cell, $48 \mathrm{~h}$ ). Adherent and suspension cells from control and treated cell cultures were harvested, washed with fluorescenceactivated cell sorting (FACS) buffer (PBS, 10\% FCS v/v and $1 \% \mathrm{v} / \mathrm{v}$ sodium azide), and stained with $5 \mu \mathrm{l}$ $0.05 \mathrm{mg} / \mathrm{ml}$ PI (Sigma) for $15 \mathrm{~min}$ before acquisition. Flow cytometry was performed using a FACSCalibur (Becton Dickinson, Hertfordshire, UK). Cell death was determined by measuring the proportion of cells staining positive for PI.

\section{Measurement of the effect of ZVAD on cell death}

To determine the mechanism of reovirus-induced cell death, melanoma cells were seeded at a known density and incubated with $50 \mu \mathrm{M}$ ZVAD (an irreversible pancaspase inhibitor-Calbiochem, Nottingham, UK) or control medium for 1 hour before reovirus infection. Cell viability was determined using PI staining, as described above.

\section{MTT assay}

Tumour cells grown to $80 \%$ confluence in $175 \mathrm{~cm}^{2}$ Falcon flasks (BD Bioscience, Oxford, UK) were harvested, counted and plated in 96-well plates at a density of $1 \times 10^{4}$ cells per well. After $24 \mathrm{~h}$, they were infected with known dilutions of reovirus in DMEM. Control wells received an equivalent volume of unmodified medium. After $96 \mathrm{~h}$ incubation, MTT reagent $(20 \mathrm{ml}$ of a solution of $5 \mathrm{mg} / \mathrm{ml}$ ) was added for $5 \mathrm{~h}$ and the assay was developed by solubilizing in $100 \mathrm{ml}$ dimethyl sulphoxide and read at $550 \mathrm{~nm}$ on a SPECTRAmax 384 plate reader (Molecular Devices, Sunnyvale, CA, USA).

Effect of Ras pathway inhibitors on reoviral cytotoxicity Cells were plated at a density of $5 \times 10^{3}$ per well in a 96well plate and the following day, they were exposed to small molecule inhibitors at $10 \mu \mathrm{M}$ for $2 \mathrm{~h}$. They were then infected with reovirus at approximately the $\mathrm{IC}_{50}$ dilution for $2 \mathrm{~h}$, after which time the cells were washed and inhibitor-containing medium was added. Cell survival was measured by MTT assay after $96 \mathrm{~h}$.

\section{Western blotting}

Melanoma cell lines were either left untreated or infected with $10 \mathrm{PFU} /$ cell reovirus for $3,8,16,24$ or $48 \mathrm{~h}$ before preparation of whole cell lysates. ${ }^{57}$ Proteins from untreated and reovirus-treated cells were electrophoresed ( $20 \mu \mathrm{g}$ protein/lane) on an $8 \%$ SDS polyacrylamide gel and transferred to a nitrocellulose filter following standard protocols. The reovirus $\mu$ protein was detected using polyclonal antireovirus goat serum (Oncolytics Biotech Inc.). $\beta$-actin was detected using a rabbit polyclonal anti- $\beta$-actin antibody (Abcam, Cambridge, UK).

\section{Progeny virus}

Cells were infected with reovirus at $10 \mathrm{PFU} /$ cell for $72 \mathrm{~h}$ and then cells and supernatants were harvested and subjected to three rounds of freeze/thaw. Viral titre was determined using a standard plaque assay on L929 cells. Fold increase in viral progeny was determined by comparison with levels of input virus.

\section{In vivo activity of reovirus in melanoma xenografts}

All procedures were approved by the Mayo Foundation Institutional Animal Care and Use Committee. To establish subcutaneous tumours, $2 \times 10^{6}$ Mel888 cells were injected subcutaneously $(100 \mu \mathrm{l})$ into the flank region of athymic nude mice (eight per group). Animals were examined daily until the tumour became palpable; at $5 \mathrm{~mm}$, tumours were injected daily for 5 days with $5 \times 10^{7}$ PFU of reovirus, UV-inactivated reovirus or PBS. Thereafter, the tumour diameter was measured thrice weekly using callipers; animals were killed when tumour size was approximately $1.0 \times 1.0 \mathrm{~cm}$ in two perpendicular directions. Tumour volume was calculated using the following Equation; $\pi / 6 \times \mathrm{d} 1 \times \mathrm{d} 2 \times \mathrm{d} 3$. 


\section{DC activation}

Immature DC were generated as described above and left untreated, treated with $250 \mathrm{ng} / \mathrm{ml}$ LPS (Sigma) or cultured with TCM from uninfected melanoma cells or cells treated with $10 \mathrm{PFU} /$ cell reovirus for $48 \mathrm{~h}$. Tumour cell supernatant was subsequently filtered to remove reovirus, using specialized filters (Millipore-successful removal of virus was confirmed by plaque assay), and then added to $\mathrm{DC}$ mixed at a 1:1 ratio with fresh $\mathrm{DC}$ media. DC were then left for $24 \mathrm{~h}$ and the expression of CD80 and CD86 examined by flow cytometry using a FACSCalibur.

\section{ELISA and luminex}

Levels of IL-18, IL-10 and IL-6 in tissue culture supernatant were measured by ELISA using matched paired antibodies (BD Biosciences-Pharmingen, Oxford, UK). Mip- $1 \alpha$, Mip-1 $\beta$ and RANTES were detected using luminex technology (Biosource, Nivelles, Belgium) according to the manufacturer's instructions.

\section{Isolation of primary melanoma cells}

Freshly isolated melanoma tissue was briefly sterilized in $70 \%$ ethanol (30 s) and chopped finely before treatment with $0.1 \mathrm{mg} / \mathrm{ml}$ collagenase in DMEM (Gibco), $10 \mathrm{mM}$ HEPES and $1 \% \mathrm{v} / \mathrm{v}$ penicillin/streptomycin (Gibco) for $2 \mathrm{~h}$ at $37^{\circ} \mathrm{C}$. Cell suspension was then passed through a $70 \mu \mathrm{m}$ cell strainer, cells were washed in complete media (DMEM, 10\% FCS, 1\% HEPES, 1\% glutamine and 1\% pen/strep) before plating into tissue culture flasks. Cells were left overnight for cells to adhere and non-adherent cells were removed. Adherent cells were cultured in complete media and frozen down in freezing media $(90 \%$ FCS, $10 \%$ dimethyl sulphoxide) prior to use.

\section{Immunofluorescence}

Primary melanoma cells were grown on chamber slides (Falcon), washed in PBS and fixed in $4 \%$ paraformaldehyde for $30 \mathrm{~min}$. Cells were subsequently washed and permeabilized using $0.3 \%$ saponin (15 min at RT) and stained with a mouse monoclonal anti-/MART-1 antibody (1:200 dilution-Santa Cruz, CA, USA) followed by goat anti-mouse FITC conjugated antibody (1:100 dilution-BD Bioscience). Fluorescent images were acquired using a Carl Zeiss Axioplan 2 imaging microscope.

\section{References}

1 Selb B, Weber B. A study of human reovirus IgG and IgA antibodies by ELISA and western blot. J Virol Methods 1994; 47: $15-25$.

2 Coffey MC, Strong JE, Forsyth PA, Lee PW. Reovirus therapy of tumors with activated Ras pathway. Science 1998; 282: 1332-1334.

3 Strong JE, Coffey MC, Tang D, Sabinin P, Lee PW. The molecular basis of viral oncolysis: usurpation of the Ras signaling pathway by reovirus. EMBO J 1998; 17: 3351-3362.

4 Strong JE, Lee PW. The v-erbB oncogene confers enhanced cellular susceptibility to reovirus infection. J Virol 1996; 70: 612-616.

5 Marcato P, Shmulevitz M, Lee PW. Connecting reovirus oncolysis and Ras signaling. Cell Cycle 2005; 4: 556-559.

6 Norman KL, Hirasawa K, Yang A, Shields MA, Lee PWK. Reovirus oncolysis: the Ras/RalGEF/p38 pathway dictates host cell permissiveness to reovirus infection. Proc Natl Acad Sci USA 2004; 101: 11099-11104.

7 Smakman N, van den Wollenberg DJ, Borel Rinkes IHM, Hoeben RC, Kranenburg O. Sensitization to apoptosis underlies KrasD12-dependent oncolysis of murine C26 colorectal carcinoma cells by reovirus T3D. J Virol 2005; 79: 14981-14985.

8 Alain T, Kim TSY, Lun X, Liacini A, Schiff LA, Senger DL et al. Proteolytic disassembly is a critical determinant for reovirus oncolysis. Mol Ther 2007; 15: 1512-1521.

9 Marcato P, Shmulevitz M, Pan D, Stoltz D, Lee PWK. Ras transformation mediates reovirus oncolysis by enhancing virus uncoating, particle infectivity, and apoptosis-dependent release. Mol Ther 2007; 15: 1522-1530.

10 Hirasawa K, Nishikawa SG, Norman KL, Alain T, Kossakowska A, Lee PWK. Oncolytic reovirus against ovarian and colon cancer. Cancer Res 2002; 62: 1696-1701.

11 Norman KL, Coffey MC, Hirasawa K, Demetrick DJ, Nishikawa SG, DiFrancesco LM et al. Reovirus oncolysis of human breast cancer. Hum Gene Therapy 2002; 13: 641-652.

12 Wilcox ME, Yang W, Senger D, Rewcastle NS, Morris DG, Brasher PMA et al. Reovirus as an oncolytic agent against experimental human malignant gliomas. J Natl Cancer Inst 2001; 93: 903-912.

13 Alain T, Hirasawa K, Pon KJ, Nishikawa SG, Urbanski SJ, Auer Y et al. Reovirus therapy of lymphoid malignancies. Blood 2002; 100: 4146-4153.

14 Polsky D, Cordon-Cardo C. Oncogenes in melanoma. Oncogene 2003; 22: 3087-3091.

15 Dumaz N, Hayward R, Martin J, Ogilvie L, Hedley D, Curtin JA et al. In melanoma, RAS mutations are accompanied by switching signaling from BRAF to CRAF and disrupted cyclic AMP signaling. Cancer Res 2006; 66: 9483-9491.

16 Garbe C, Eigentler TK. Diagnosis and treatment of cutaneous melanoma: state of the art 2006. Melanoma Res 2007; 17: 117-127.

17 Benencia F, Courrèges MC, Conejo-García JR, Mohamed-Hadley A, Zhang L, Buckanovich RJ et al. HSV oncolytic therapy upregulates interferon-inducible chemokines and recruits immune effector cells in ovarian cancer. Mol Ther 2005; 12: 789-802.

18 Kedl RM, Rees WA, Hildeman DA, Schaefer B, Mitchell T, Kappler $\mathrm{J}$ et al. $\mathrm{T}$ cells compete for access to antigen-bearing antigen-presenting cells. J Exp Med 2000; 192: 1105-1113.

19 Diaz RM, Galivo F, Kottke T, Wongthida P, Qiao J, Thompson J et al. Oncolytic immunovirotherapy for melanoma using vesicular stomatitis virus. Cancer Res 2007; 67: 2840-2848.

20 Schirrmacher V. Clinical trials of antitumor vaccination with an autologous tumor cell vaccine modified by virus infection: improvement of patient survival based on improved antitumor immune memory. Cancer Immunol Immunother 2005; 54: 587-598.

21 Schulz O, Diebold SS, Chen M, Näslund TI, Nolte MA, Alexopoulou $\mathrm{L}$ et al. Toll-like receptor 3 promotes cross-priming to virus-infected cells. Nature 2005; 433: 887-892.

22 Hirasawa K, Nishikawa SG, Norman KL, Coffey MC, Thompson $\mathrm{BG}$, Yoon $\mathrm{C}$ et al. Systemic reovirus therapy of metastatic cancer in immune-competent mice. Cancer Res 2003; 63: 348-353.

23 Qiao J, Wang H, Kottke T, White C, Twigger K, Diaz RM et al. Cyclophosphamide facilitates antitumor efficacy against subcutaneous tumors following intravenous delivery of reovirus. Clin Cancer Res 2008; 14: 259-269.

24 Bennett DC, Cooper PJ, Hart IR. A line of non-tumorigenic mouse melanocytes, syngeneic with the B16 melanoma and requiring a tumour promoter for growth. Int J Cancer 1987; 39: 414-418.

25 Tyler KL, Squier MK, Rodgers SE, Schneider BE, Oberhaus SM, Grdina TA et al. Differences in the capacity of reovirus strains to induce apoptosis are determined by the viral attachment protein sigma 1. J Virol 1995; 69: 6972-6979.

26 Connolly JL, Dermody TS. Virion disassembly is required for apoptosis induced by reovirus. J Virol 2002; 76: 1632-1641. 
27 Clarke P, Tyler KL. Reovirus-induced apoptosis: a minireview. Apoptosis 2003; 8: 141-150.

28 Lee PW, Hayes EC, Joklik WK. Characterization of anti-reovirus immunoglobulins secreted by cloned hybridoma cell lines. Virology 1981; 108: 134-146.

29 Ikeda Y, Nishimura G, Yanoma S, Kubota A, Furukawa M, Tsukuda M. Reovirus oncolysis in human head and neck squamous carcinoma cells. Auris Nasus Larynx 2004; 31: 407-412.

30 Melcher A, Gough M, Todryk S, Vile R. Apoptosis or necrosis for tumor immunotherapy: what's in a name? J Mol Med 1999; 77: 824-833.

31 Crittenden MR, Thanarajasingam U, Vile RG, Gough MJ. Intratumoral immunotherapy: using the tumour against itself. Immunology 2005; 114: 11-22.

32 Sinkovics JG. Viral oncolysates as human tumor vaccines. Int Rev Immunol 1991; 7: 259-287.

33 Mocellin S, Wang E, Marincola FM. Cytokines and immune response in the tumor microenvironment. J Immunother 2001; 24: 392-407.

34 Beckebaum S, Zhang X, Chen X, Yu Z, Frilling A, Dworacki G et al. Increased levels of interleukin-10 in serum from patients with hepatocellular carcinoma correlate with profound numerical deficiencies and immature phenotype of circulating dendritic cell subsets. Clin Cancer Res 2004; 10: 7260-7269.

35 Shurin MR, Shurin GV, Lokshin A, Yurkovetsky ZR, Gutkin DW, Chatta $G$ et al. Intratumoral cytokines/chemokines/growth factors and tumor infiltrating dendritic cells: friends or enemies? Cancer Metastasis Rev 2006; 25: 333-356.

36 Schuler G, Schuler-Thurner B, Steinman RM. The use of dendritic cells in cancer immunotherapy. Curr Opin Immunol 2003; 15: 138-147.

37 Robbins PF, Kawakami Y. Human tumor antigens recognized by T cells. Curr Opin Immunol 1996; 8: 628-636.

38 Elder D. Tumor progression, early diagnosis and prognosis of melanoma. Acta Oncol 1999; 38: 535-547.

39 Riker AI, Radfar S, Liu S, Wang Y, Khong HT et al. Immunotherapy of melanoma: a critical review of current concepts and future strategies. Expert Opin Biol Ther 2007; 7: 345-358.

40 Kasper B, D'Hondt V, Vereecken P, Awada A. Novel treatment strategies for malignant melanoma: a new beginning? Crit Rev Oncol Hematol 2007; 62: 16-22.

41 Arpaia N, Cassano N, Vena GA. Regressing cutaneous malignant melanoma and vitiligo-like depigmentation. Int J Dermatol 2006; 45: 952-956.

42 Daniels GA, Sanchez-Perez L, Diaz RM, Kottke T, Thompson J, Lai $\mathrm{M}$ et al. A simple method to cure established tumors by inflammatory killing of normal cells. Nat Biotechnol 2004; 22: 1125-1132.

43 Sanchez-Perez L, Kottke T, Daniels GA, Diaz RM, Thompson J, Pulido J et al. Killing of normal melanocytes, combined with heat shock protein 70 and CD40L expression, cures large established melanomas. J Immunol 2006; 177: 4168-4177.

44 Shmulevitz M, Marcato P, Lee PW. Unshackling the links between reovirus oncolysis, Ras signaling, translational control and cancer. Oncogene 2005; 24: 7720-7728.

45 Gray-Schopfer VC, da Rocha Dias S, Marais R. The role of B-RAF in melanoma. Cancer Metastasis Rev 2005; 24: 165-183.

46 Matzinger P. An innate sense of danger. Semin Immunol 1998; 10: 399-415.

47 Zeng J, Fournier P, Schirrmacher V. Induction of interferon-alpha and tumor necrosis factor-related apoptosis-inducing ligand in human blood mononuclear cells by hemagglutinin-neuraminidase but not F protein of Newcastle disease virus. Virology 2002; 297: 19-30.

48 Alexopoulou L, Holt AC, Medzhitov R, Flavell RA. Recognition of double-stranded RNA and activation of NF-kappaB by Tolllike receptor 3. Nature 2001; 413: 732-738.

49 Williams ME, Cox DC, Stevenson JR. Rejection of reovirustreated L1210 leukemia cells by mice. Cancer Immunol Immunother 1986; 23: 87-92.

50 Steele TA, Cox DC. Reovirus type 3 chemoimmunotherapy of murine lymphoma is abrogated by cyclosporine. Cancer Biother 1995; 10: 307-315.

51 Moser B, Wolf M, Walz A, Loetscher P. Chemokines: multiple levels of leukocyte migration control. Trends Immunol 2004; 25: 75-84.

52 Detournay O, Mazouz N, Goldman M, Toungouz M. IL-6 produced by type I IFN DC controls IFN-gamma production by regulating the suppressive effect of CD4+ CD25+ regulatory T cells. Hum Immunol 2005; 66: 460-468.

53 Taub DD, Ortaldo JR, Turcovski-Corrales SM, Key ML, Longo DL, Murphy WJ et al. Beta chemokines costimulate lymphocyte cytolysis, proliferation, and lymphokine production. J Leukoc Biol 1996; 59: 81-89.

54 Wegiel B, Bjartell A, Culig Z, Persson JL. Interleukin-6 activates PI3K/Akt pathway and regulates cyclin A1 to promote prostate cancer cell survival. Int J Cancer 2008; 122: 1521-1529.

55 Araki S, Omori Y, Lyn D, Singh RK, Meinbach DM, Sandman Y et al. Interleukin-8 is a molecular determinant of androgen independence and progression in prostate cancer. Cancer Res 2007; 67: 6854-6862.

56 Errington F, Jones J, Merrick A, Bateman A, Harrington K, Gough $\mathrm{M}$ et al. Fusogenic membrane glycoprotein-mediated tumour cell fusion activates human dendritic cells for enhanced IL-12 production and T-cell priming. Gene Therapy 2006; 13: 138-149.

57 Mirski SE, Evans CD, Almquist KC, Slovak ML, Cole SPC. Altered topoisomerase II alpha in a drug-resistant small cell lung cancer cell line selected in VP-16. Cancer Res 1993; 53: 4866-4873. 